Petar B. Petrović Belgrade University, Faculty of Mechanical Engineering,

Department for Production Engineering, Academy of Engineering Sciences of Serbia - AINS

\title{
INDUSTRIALIZATION - Quantitative Framework, Technological Dimension and the Future we Cannot Ignore
}

\author{
UDC: $330.341 .424 ; 005.591 .6$
}

DOI: 10.7595/management.fon.2014.0006

SPIN' 13, Belgrade, 05-06. November 2013.

The paper presents some results of the research that has been systematically conducted over a long period at the Academy of Engineering Sciences of Serbia (AINS) in the area of modern industrial and especially manufacturing technologies, as well as interactions among engineering sciences, technology and the society. The issue of industrialization is closely connected with this research and it is in this context that fresh insights are offered into industrial development, ones that are essentially different from the prevailing stereotypes that have for years been dominant in the management of the economic system in Serbia. Following the introductory chapter that gives a short review of the genesis of Serbian industry, the author offers a view of the industrial system through three chapters: 1) Industrial system of Serbia - Quantification, problems and implications; 2) Restoration and recovery framework - Industrial policies and strategic framework for fast and sustainable exiting the crisis condition; and 3) New industry of Serbia - Serbian industry transformation in the context of European integration processes, the future context (factories of the future), challenges and needs, where special attention is paid to the analysis of the problem of science pragmatization and its active part in the process of industrialization in the framework of the vertical and horizontal technology transfer, as part of the European integrations of Serbia.

Keywords: Industrijalization, industrial policies, technology.

\section{Introduction}

Creating a vital and globally competitive industry system is a rather long process in any economy. In addition to massive investmants into building a complex industrial infrastructure, it requires a long-term systemic planning of technological development as well as the development of adequate human resources through permanent highly qality education.

A knowledge-based society primarily lies on the economy of knowledge, and the economy of knowledge itself is based on the knowledge-based industry, industry that develops its competitiveness on the technological strength and highly educated human resources and sustains its vitality on extensive development processes based on a continual technological innovation of products, manufacturing processes, organizational structure and marketing activities.

A knowledge-based industry dominantly lies on human, rather than on natural resources.

The industrialization of an economic system is not possible without a vigorous technological development and equally vigorous engineering. The primary generator of human resources is the system of education. In practice, the development of industrial and educational systems are two intertwining processes, strongly interconnected, highly inert, and characterised by an inherent time asynchronism. The industrial and educational systems are functionally complementary systems and their development in a stable social environment is always a coevolutionary process. 
The beginnings of industrialization of Serbia date back into the mid-nineteen century, in the times when the country established its statehood and its national cohesion, the times that are in many ways similar to the times we live in today. Before exactly 160 years the first Serrbian factory began its successful operation in Kragujevac. The factory was the Kragujevac gun-factory in which 6 cannon barrels were first cast on 27th October,1853, the result of many a year of efforts and careful planning. It is almost two centuries since that day, however, this event is of paramount importance for the time in which we now live and the difficulties we encounter in solving a host of economic problems accumulated so far. The activities preceding this condition lasted for decades, both in the field of building physical infrastructure for production and in that of developing the intellectual potential for the job. It was in 1853, at the College (the Lycée), the first higher education institution in Serbia, the Department of natural and technical sciences was founded to train engineers. It was already at that time that Serbia recognized the causality relations among the industrial development, engineering and technology. Simultaneously, Serbia made its best efforts to accomplish the technology transfer through imports of then high-technology equipment and attract foreign experts in industrial production (reducing technological gap through technology convergence concept). The results were fascinating. In a period no longer than ten years Serbia almost entirely substituted its imports (which in the context of defence technologies also had other implications besides economic ones), launched its own operation activities in mastering the technology of making grooved-barrel guns (an extremely complex technology at the time) and, which is almost incredible, exported high-technology products of its own, for the first time, in that it sold 24 seemless-barrel six-pounder to the neighbouring Romania. The further industrial development followed an exponential model, however, it went in waves - our industry would be destroyed during the wars; during the periods of peace we would rebuild it.

This plenary paper focuses upon technological and engineering components of the industrialization process, starting from the fact that technology and engineering make the key constituents of the industrial system and, consequently, the key challenge for the success and a long-term sustainability of this process. The topic is organized in three chapters:

1. Industrial system of Serbia - quantification, problems and implications;

2. Revitalization and recovery framework - industrial policies and strategic framework for fast and sustainable exiting the crisis conditions;

3. New industry of Serbia - transforming Serbian industry in the context of integration processes, the future context (factories for the future), challenges and needs.

The paper ends with the list of reference used to write the report, as well as literature offering detailed explanation of the used terminology and the author's attitudes.

\section{Industrial system of Serbia}

Quantification of the state of the art and the preceding context - problems and implications

The political and economic crisis that has for the last 25 years been present in the region of ex-Yugoslavia in various forms has had extensive implications for the industrial system of the region. In case of Serbia, the final outcome is a serious deindustrialization of the economic system with a development component at a standstill. The deindustrialization process was so intensive that it can be said to have entirely annihilated all that was developed throughout the twentieth century. An accurate quantification for a broader period of 50 years is presented in Figure 1, in the described time series of three key aggregate indicators: 1) scope of industrial production, 2) number of workers in industry and 3) contribution of industrial production to the gross domestic product, GDP. The graphs below show an extremely high rise in development activities in the year 1989, when Serbian industry employed 1,032,000 workers (one in ten citizens was employed in industry), when one out of three dinars of the gross domestic product was earned in the industrial production and when highly dynamic technological processes worked towards gradually transforming Serbia into a developed industrial economy. The preceding three decades of development were characterised by a highly intensive industry growth that can be compared to that of fastest growing Asian economies today. 


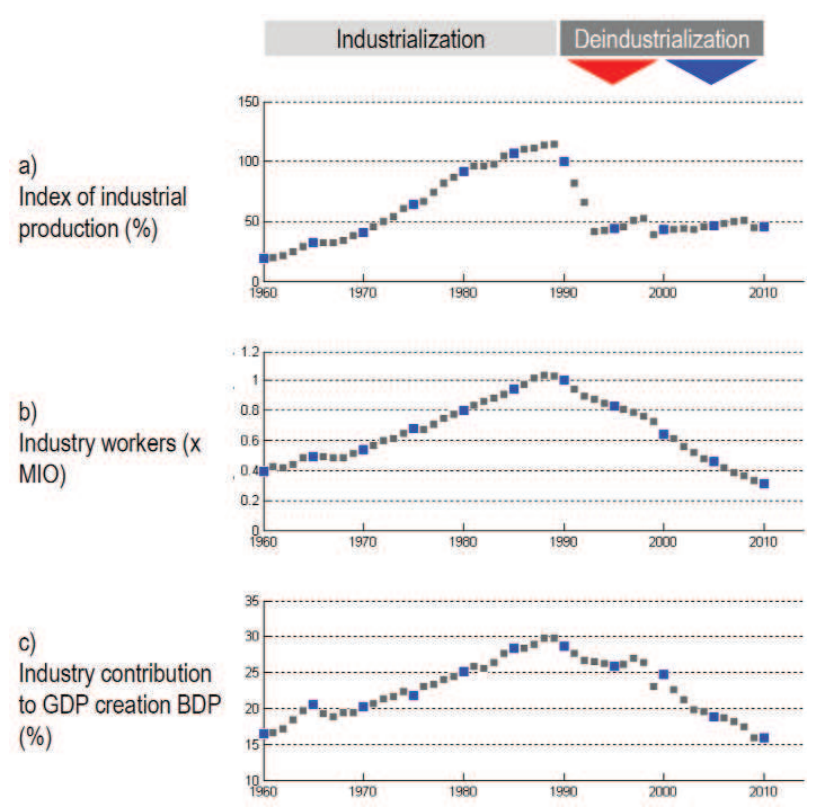

Figure 1: Comparative presentation of basic aggregate indicators of the state of the art of industry in Serbia in the 1960 - 2010 period: a) scope of industrial production,

b) number of workers in industry and c) contribution of industrial production to the GDP creation

(all for the manufacturing industry domain; source: the Serbian Development Institute).

The above described semi-centenial time frame can be divided into three characteristic periods:

\begin{tabular}{|l|l|}
\hline PERIOD 1 - & $\begin{array}{l}\text { Period of industrialization and technical expansion: } \\
\text { The period from } 1960 \text { to } 1990: \text { three decades characterised by accelerated but } \\
\text { steady technological development and a dynamic growth in the industrial } \\
\text { component in the Serbian economy (the context preceding the crisis). The average } \\
\text { growth of industrial production: } 7.8 \% \text { annually; data for } 1990: \mathrm{IP}_{1990}=100 \%, \\
998.000 \text { employed in industry, } 28.6 \% \text { BDP); }\end{array}$ \\
\hline PERIOD 2- & $\begin{array}{l}\text { Period of disintegration of the integral industrial system of Yugoslavia: } \\
\text { The period from } 1991 \text { to } 2000: \text { a decade characterised by the disintegration of } \\
\text { Yugoslavia, hyperinflation, economic sanctions enforced by the UN, military conflict } \\
\text { with the NATO alliance leading to the isolation of Serbia, fragmentation of } \\
\text { production technological chains and loss of markets. Data for } 2000: \mathrm{IP}_{1990}=43.3 \%, \\
643.000 \text { employed in industry, 24.7\% BDP); }\end{array}$ \\
\hline PERIOD 3 - & $\begin{array}{l}\text { Period of deindustrialization: } \\
\text { The period from } 2001 \text { until the present time: a decade characterised by an intensive } \\
\text { ownership transformation and an unsuccessful transition process focused upon the } \\
\text { economy of services and an extremely liberalized market in which Serbia has also } \\
\text { lost its human, infrastructure and programme resources. Data for } 2000: \mathrm{P}_{1990}= \\
\text { 45.9\%, 312.000 employed in industry, 15.9\% BDP); }\end{array}$ \\
\hline
\end{tabular}

From the point of view of the dynamic component, there is an evident and striking discontinuity in the 1989 development. This is the moment when the industrial system in Serbia plunged into a deep crisis and this condition has basically remained the same until today. The last two decades are characterised by a virtually zero average growth of production, a permanent fall in the number of industrial labour force and consequently a reduced contribution of industry in the GDP creation presently amounting to $15 \%$, considerably lower in comparison with the world average of $31 \%$ or the European average of $25 \%$. The character of these retrograde processes can be described through a comparison with the pre-crisis period: the scope of in- 
dustrial production in 2010 equalled to that achieved in 1970 (however, without the dynamic component), while the number of employees in industry and the contribution of industry to the GDP creation are lower in comparison to those of 1960 .

In contrast to the deindustrialization processes in developed economies which is in itself a planned process of transforming the industrial into the post-industrial, or service, economy, deindustrialization in Serbia was random in character. The erosion processes were so intensive that the 2008 economic crisis that spilled over into our economic system was of a secondary importance. What was dominant was our own, internal crisis.

In addition to the above stated, evident is the process of an intensive erosion of the technological background of industry, with clearly evident trends towards work-intensive sectors, a dominant production of low value added products and a negligible share of the development component in all industry sectors (engineering development processes, primarily the designing of products, production processes and organizational structures).

Certain sectors, especially in the high technology and medium-high technology areas have completely disappeared. For example, the Serbian industry no longer produces machine tools, industry robots and transfer lines for automobile and other metal processing industries, and it is this sector, the metal processing sector with its generic properties in the period preceding 1990, that was the generator of industry development, a vital component of technological independence and a long-term stability of the Serbian economy. Manufacturing of these products simultaneously largely contributed both to the exports and to the reputation of our industry globally. A very good example for this can be a mass production and then a mass export of cnc processing centres, especially to the USA market that was once a cradle of this high-grade and highly complex technology. This programme was realized in the late 1980s as one of strategic projects resulting from collaboration between domestic industry and domestic science. These activities were simultaneously accompanied by an intensive interaction with the curricula at the mechanical engineering and electrical engineering faculties, including post-graduate studies with master and doctoral theses, which in turn produced domestic experts, highly specialised in the areas of cnc technologies, robotics, mechatronics, as well as a wide range of computer applications in industrial production and business system management, the then advanced technologies, strategically important for all industry sectors (horizontal transformational technologies and technological enablers).

The developmental and educational activities were followed by the construction of highly specialized research and development laboratories, new technology centres, while the leading companies developed specialized research and development units within their business systems, including even institutes (e.g., the LOLA Institute as a specialized research and development unit in the area of numeric and flexible production technologies within the then LOLA Corporation). This example illustrates how highly complex industry structure was at the time, characterised by a wide scope and a large number of parallel processes reaching far beyond the industry framework.

Similar cases of the erosion of technological structure of the Serbian industry are present in other sectors, such as in the electrical and electronic device manufacturing sector, transportation vehicles (automobiles, trucks, buses and aircraft) sector, or agricultural machinery and equipment sectors. Some of these sectors have practically perished whereas the rest remain almost paralyzed, on the verge of existence. The devastation of these sectors blocked the entire pyramid of manufacturing industry since these highly technological sectors that produced the finished products of high technical complexity took with them and seriously harmed other industry sectors in Serbia and caused the end of hundreds of small and medium-sized enterprises that based their production programme on cooperation relations, specializing in one niche of products, i.e., components of the above mentioned finished products of metal and electronic industries.

High R\&D intensity sectors (HT - intensity above 5\%) include e.g. Pharmaceuticals \& biotechnology; Health care equipment \& services; Technology hardware \& equipment; Software \& computer services, (HIGH technologies).

Medium-high R\&D intensity sectors (MHT - between $2 \%$ and $5 \%$ ) include e.g. Electronics \& electrical equipment; Automobiles \& parts; Aerospace \& defence; Industrial engineering \& machinery; Chemicals; Personal goods; Household goods; General industrials; Support services, (MEDIUM-HIGH technologies). 
Medium-low R\&D intensity sectors (MLT - between 1\% and 2\%) include e.g. Food producers; Beverages; Travel \& leisure; Media; Oil equipment; Electricity; Fixed line telecommunications, (MEDIUM-LOW technologies).

Low R\&D intensity sectors (LT - less than 1\%) include e.g. Oil \& gas producers; Industrial metals; Construction \& materials; Food \& drug retailers; Transportation; Mining; Tobacco; Multi-utilities, (LOW technologies).

Research is defined as genuine and planned exploration undertaken for the purpose of attaining new scientific knowledge and appreciation.

Development is defined as the implementation of the research results or of other knowledge in planning and designing for the purpose of producing new or significantly improved materials, devices, products, processes, systems or services, prior to commencing a commercial production or use.

R \&D intensity is the ratio between investment into $R \& D$ and the net sales of a given company or a group of companies.

\section{Tehnološki profil industrije}

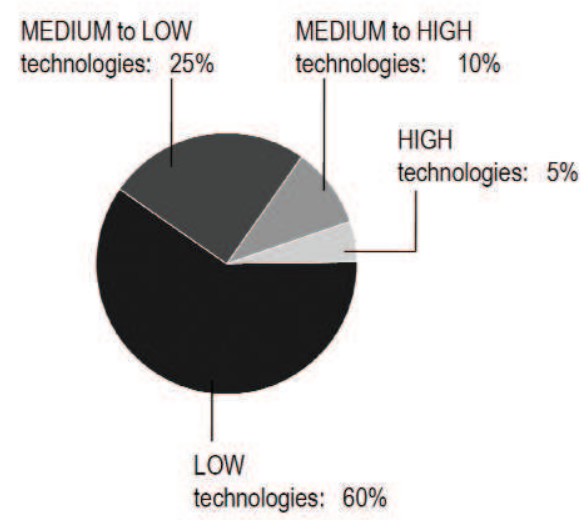

Figure 2: Technological profile of industry in Serbia for the year 2008 according to the OECD industry sector technological intensity ranking model [34].

Serbia nowadays lacks the competence to develop or to produce highly technological products it used to produce twenty and even thirty years ago. The profile of the technological structure of Serbia for the year 2008 (Figure 2) devised in accordance with the OECD ranking of the technology intensity of industry sectors ( $\mathrm{LT}-\mathrm{MLT}-\mathrm{MHT}-\mathrm{HT}$ ) is defined by the following approximative ratios: $65-25-5-5$ according to the number of companies, or 51-23-19-7 according to the number of employees. It is evident that the technology development process in the two crisis decades was inverse in its nature.

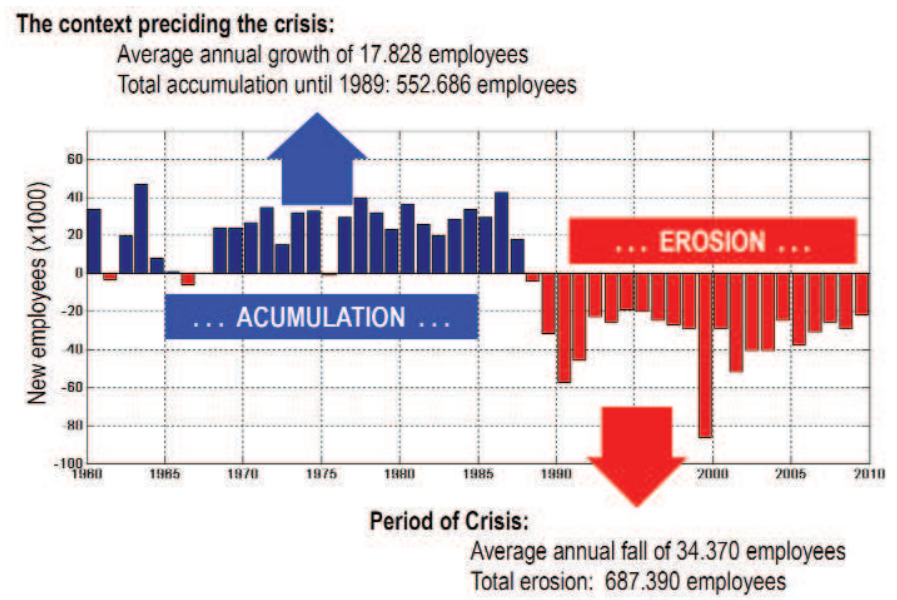




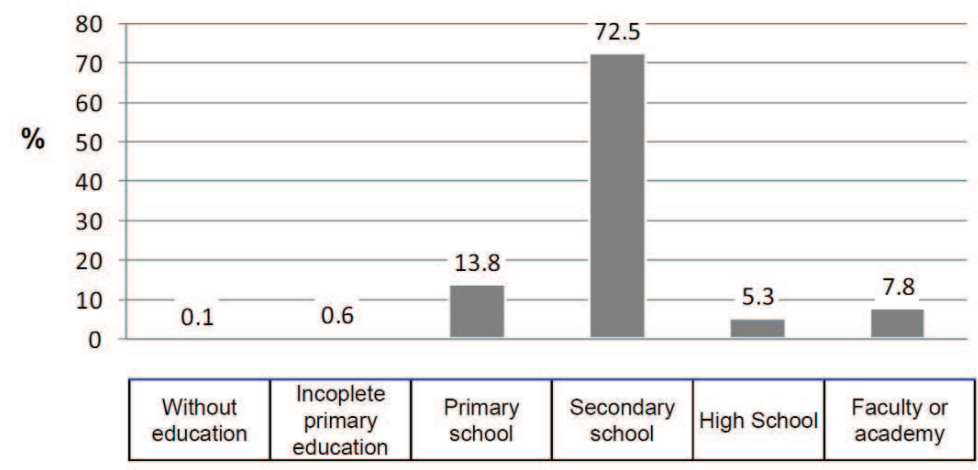

Figure 3: Dynamics of accumulation and erosion of intellectual capital for industrial production (inferred from the graph in Figure 1a). Figure below: Qualification profile of industry of Serbia for manufacturing workers 15-65 years of age, employed on any basis, 2011; age structure, especially in the

development period is catastrophic, the average age is estimated to be over 55, although this is not reported in the official statistics, nor are professional competencies by qualification profiles.

The twenty years long crisis has devastated the intellectual capital of Serbia in the areas of technology and industrial production. Its consequences are evident in the technology profile and and the diversity of products we create.

In order that the industrialization process in the technology domain be understood, it is necessary that the difference between the worker and the workplace should be perceived correctly. It is the worker that carries the productive knowledge, not the workplace!

The dynamic component of the development of human resources can be inferred from the graph presented in Figure $1 \mathrm{~b}$ and thus an insight can be obtained into the real scope of damage caused by the development discontinuity of the 1990s. The ordinate in the graph in Figure $3 a$ shows the number of new industrial workers. The positive value presents employment, while the negative one signifies redundancies. Employment is dominant until 1989. During the period of thirty years an average of 18.000 workers were employed annually, which resulted in an accumulation of over half a million of industrial workers. The continuity of the process indicates a continual accumulation of the productive technological knowledge in the industrial system of Serbia. The period of crisis is characterised by an enormous erosion, twice faster than accumulation. In twenty years Serbia lost almost 700.000 workers, namely, 34.000 workers annually on average. Besides, the 2011 statistics shows that the qualification profile of the remaining ones is highly unfavourable, with a small number of those with tertiary education (the strategic orientation of Europe is that the industry sector should reach an unbelievable number $40 \%$ of employees with tertiary education aged 30 to 40 , the deadline for such an ambitious plan being the year 2020 .

\section{The revitalization and recovery framework}

Industrial policies and strategic framework for fast and sustainable exiting the crisis condition.

Industry is the driving force of any economy, hence the condition of industry has had a paralysing effect upon the overall economic and social development of Serbia. It is surprising that even in such difficult economic conditions, after 25 years of stagnation, the industry of Serbia still makes a key component of the economic system, generating the majority of jobs in the material production sectors (not in agriculture or construction industry) and holding a largest share in creating new value that is partly placed into exports where industry products are dominant (over $80 \%$ ). The quantification of this statement is partly presented in Table 1 . It is characteristic that the dominant share in the industry structure, which itself is composed of three basic industrial sectors, 1) manufacture, 2) mining and 3) power engineering and water supply, belongs to manufacturing industry, far beyond any other material production sectors. What is surprising in this context is the prevailing attitudes as regards the strategic orientation of the material production sector development that almost neglect the manufacturing industry, that is, what English terminology mentions as manufacturing. Even in case of the service sector that employs twice as many workers in comparison with the manufacturing sector, manufacturing is a dominant job generator. 
Table 1: Employment in Serbia in 2010

\begin{tabular}{|c|c|c|c|c|c|}
\hline \multicolumn{6}{|c|}{ Employment in 2010 (annual average) } \\
\hline \multicolumn{2}{|c|}{ Total of employees } & \multicolumn{4}{|l|}{1775000} \\
\hline \multicolumn{2}{|c|}{ Employed with legal entities } & \multicolumn{4}{|l|}{1348000} \\
\hline \multicolumn{2}{|r|}{ Entrepreneurs and employed with entrepreneurs } & \multicolumn{4}{|l|}{427000} \\
\hline \multicolumn{2}{|c|}{ Employee structure per sector } & \multicolumn{2}{|c|}{ Number of workers } & \multicolumn{2}{|c|}{ Share (\%) } \\
\hline \multicolumn{2}{|l|}{ TOTAL } & \multicolumn{2}{|l|}{1348000} & \multicolumn{2}{|c|}{$100 \%$} \\
\hline \multicolumn{6}{|c|}{ Sector } \\
\hline \multirow[t]{7}{*}{ Production } & & 467000 & \multicolumn{3}{|c|}{36.2} \\
\hline & Agriculture, forestry and fishing & & 36000 & & 2.7 \\
\hline & Mining & & 22000 & & 1.6 \\
\hline & Manufacturing & & 296000 & & 22.0 \\
\hline & Energy, gas and steam supply & & 28000 & & 2.1 \\
\hline & Water supply and waste water management & & 32000 & & 2.4 \\
\hline & Construction & & 73000 & & 5.4 \\
\hline \multirow[t]{14}{*}{ Services } & & \multicolumn{2}{|l|}{881000} & \multicolumn{2}{|c|}{63.8} \\
\hline & Retail and wholesale trade & & 184000 & & 13.6 \\
\hline & Transportation and storage & & 87000 & & 6.5 \\
\hline & Accomodation and food catering services & & 21000 & & 1.6 \\
\hline & Information and communication & & 37000 & & 2.7 \\
\hline & Finance and insurance & & 39000 & & 2.9 \\
\hline & Real estate transactions & & 3000 & & 0.2 \\
\hline & $\begin{array}{l}\text { Professional, scientific, innovation and techn. } \\
\text { services }\end{array}$ & & 53000 & & 3.9 \\
\hline & Administrative and auxiliary services & & 31000 & & 2.3 \\
\hline & $\begin{array}{l}\text { Governance, defence and obligatory health } \\
\text { insurance }\end{array}$ & & 70000 & & 5.2 \\
\hline & Education & & 137000 & & 10.2 \\
\hline & Health care and welfare plan & & 160000 & & 11.9 \\
\hline & Arts, entertainment and recreation & & 22000 & & 1.6 \\
\hline & Other services & & 14000 & & 1.0 \\
\hline \multicolumn{6}{|c|}{$\begin{array}{l}\text { Source: The Statistical Office of the Republic of Serbia, (2012): Monthly Statistical Bulletin 12/2011, Bulletin 550, ISSN } \\
2217-2092 \\
\text { Notes: Since January } 2011 \text { the job description is applied following the NACE Rev.2 (Official Gazette of the Republic of } \\
\text { Serbia 54/2010) / of the EU job description system and is comparable with the UN job description system ISIC - } \\
\text { rev.4. } \\
\text { The term employee means all physical persons fully employed by the employer (those employed on the basis of } \\
\text { temporary work contract or a contract on temporary jobs are not considered to be employed persons). }\end{array}$} \\
\hline
\end{tabular}

Regardless of the model of the economic system, of whether the "invisible hand of the market" is present to a larger or a smaller extent, the key role in the development of the industry system belongs to the state. The state uses adequate industrial policies to strategically guide or coordinate industrial development, primarily the technological development as a key component of its competitiveness. The role of the state is particularly important in the times of crisis, when the systems of extreme complexity, which industry certainly is, require the presence of a hierarchically superior system that will coordinate activities in order to correct anomalies on the subordinate levels thus stabilizing the system in as short a time as possible. The example for this thesis can be an extract from the current industrial policy of the European Union. This is, in fact, an amended version of the original document the European Commission adopted for the period 2010 - 2020, which had to be subject to essential changes after only a year, including the changes in the pillars on which industrial policy was planned to lie, [4], [5]. This document, adopted on 10th October, 2012 and publically presented at the World Manufacturing Forum, Stutgardt, Germany, 2012 (see Figure 4) states the following [26]:

At a time when financial problems persist, Europe needs its real economy more than ever to underpin the recovery of economic growth and jobs. Our industry is well placed to assume this role: Europe is a worldleader in many strategic sectors such as automotive, aeronautics, engineering, space, chemicals and 
pharmaceuticals. Industry still accounts for 4/5 of Europe's exports and $80 \%$ of private sector R\&D investment comes from manufacturing. ....

Industrial activities also have important spillover effects on production and employment in other sectors. For every 100 jobs created in industry, it is estimated that between 60 and 200 new jobs are created in the rest of the economy, depending on the industrial sector.

...

Europe needs to reverse the declining role of industry in Europe for the 21st century. This is the only way to deliver sustainable growth, create high-value jobs and solve the societal challenges that we face.

This Communication proposes a partnership between the EU, its Member States and industry to dramatically step up investment into new technologies and give Europe a competitive lead in the new industrial revolution. After an extensive public consultation, the Commission proposes to jointly focus investment and innovation on six priority action lines: advanced manufacturing technologies, key enabling technologies, biobased products, sustainable industrial and construction policy and raw materials, clean vehicles, smart grids.

However, the harsh impact of the economic crisis on several Member States, the subsequent economic stagnation in the EU and the deteriorating outlook for the global economy have given a new urgency to this Mid-term Review of the Industrial Policy.

\section{THE PILLARS FOR A REINFORCED INDUSTRIAL POLICY: INVESTMENT IN INNOVATION, BETTER MARKET CONDITIONS, ACCESS TO CAPITAL AND HUMAN CAPITAL AND SKILLS}

The Commission proposes a proactive approach to industrial policy based on the following four main elements.

1. First, the EU must provide the right framework conditions to stimulate new investments, speed up the adoption of new technologies and boost resource efficiency. These include technical regulations and Internal Market rules, as well as accompanying measures such as infrastructure and R\&D/innovation projects. As a first step, six priority areas for immediate action are proposed in this Communication.

2. Secondly, urgent improvements in the functioning of the Internal Market are needed. They are presented here and in the Single Market Act II, and are reflected in the country-specific recommendations issued to Member States in the context of the European Semester. They will contribute to reinvigorate trade in the Internal Market.

3. Opening up international markets will also speed up recovery. The fast-growing emerging economies of the world offer new export opportunities for EU firms, especially SMEs. Investment and innovation are not possible without adequate access to finance. Public resources have already been mobilised to sustain investment in innovation, especially by SMEs. However, only unlocking private funds can ensure the level and sustainability needed to finance investment by EU companies. Improving access to capital markets is therefore another crucial challenge to increase our competitiveness.

4. Finally, accompanying measures to increase investment in human capital and skills are key to the success of industrial policy. Policies aimed at job creation and tools to anticipate skills needs are necessary to equip the labour force for industrial transformations.

The above quoted extract from the European Commission regarding industrial policy shows that strategic documents of this type are actively implemented, their implementation is actively monitored and corrected if necessary. In contrast to this practice, Serbia conducts its industrial development without a strategy, although the strategy does exist formally. The present strategy and industrial development policy of Serbia for the 2011 - 2020 period, adopted by the Government of the Republic of Serbia in June 2011[11] recognise the difficulties the industry is in, the neglect characterising its development and implications resulting from such a situation and offer concrete measures for exiting the crisis and launching a sustainable spiral of technological development. The primary strategic goal of Serbia stated in this document is a sustainable and dynamic development of industry that can easily fit into the single market of the European Union and endure the competitive pressures of its member states. 


\section{WORLD MANUFACTURING FORUM 2012}

Smart Policies for Global Manufacturing Innovation

16 - 18 October 2012, Stuttgart, Germany

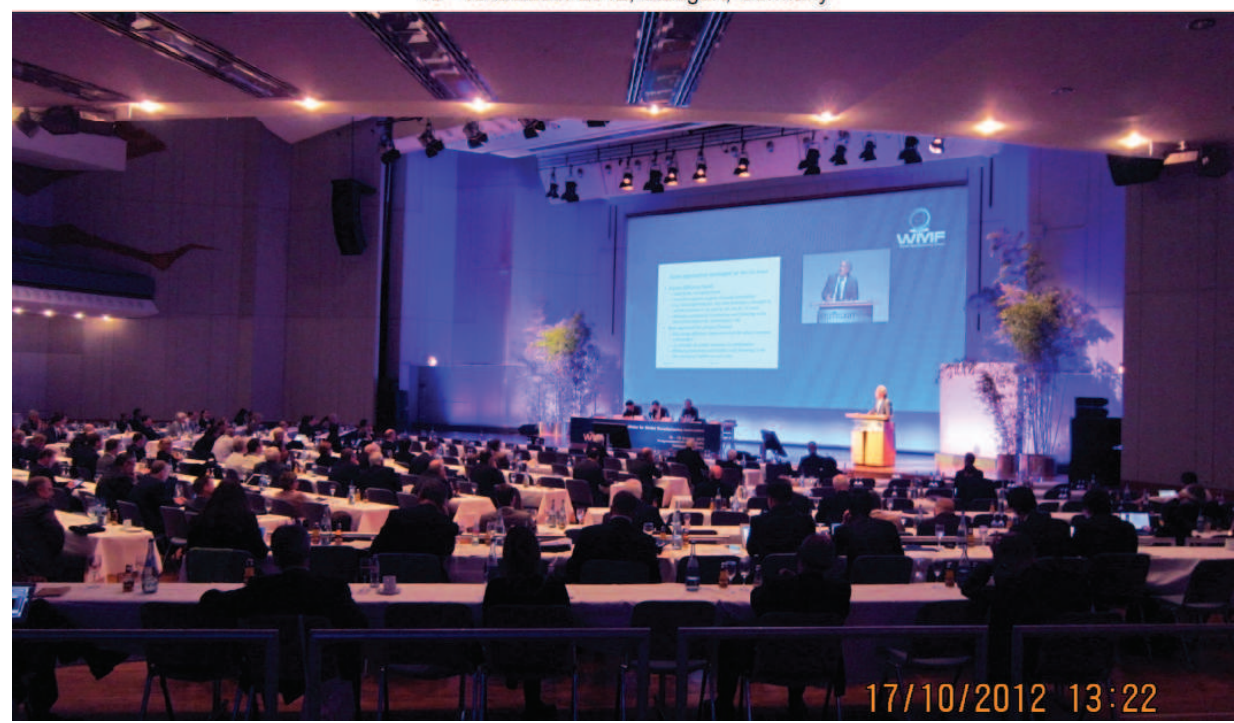

Figure 4: A photo from one of the plenary sessions of the World Manufacturing Forum held in October 2012, where the President of the European Commission addressed the forum participants, reputed scientists in the technical and economic sciences domain, directors of industrial companies, creators of industrial policies and other interested parties (participation on invitation) explaining a new, modified industrial policy of the European Union until 2020.

Among other things, the present strategy and policy of the industrial development of Serbia defines the frameworks for the recovery of industry and these comprise three basic instruments:

\section{Revitalization}

An initial impuls to the recovery process through consolidation of the existing production resources, large companies and industrial systems in particular, and enabling them to function so that they should serve as crystal nuclei around which the clusters of small and medium-sized companies will be formed.

\section{Reengineering}

Expansion in the present framework through the technological modernization of the LMT sector and a gradual introduction of high technology contents.

\section{Development and growth}

Change in the technological profile of industry, through the migration of the core of industrial production from dominantly low-technology sectors towards the high-technology ones.

Unlike the present practice, the recovery and and the development expansion of industry are, in the framework of these instruments, related to the technology development and a visibly endogenous component, as well as to an active role of the state (market does affect the overall industrial development, however, it lacks an adequate regulatory capacity to stabilize the system in case of large-scale disruptions).

Observed on a time axis, the listed strategic programme instruments are realized stepwise, thus ensuring a harmonized process, through convergence, stability, and, in a long term, sustainability of the recovery and transformation processes. Revitalization, reengineering and developmental expansion are three key instruments meant to end a two-decade stagnation and erosion of industry tissue, that is, to stop the deindustrialization process and launch the process of industrialization, the recovery of thus eroded basis. The listed instruments are elaborated in detail in the basic document of the current (official) industrial policy, while hereinafter only the key attitudes are stated, with speciall emphasis on technology and human resources.

STAGE I - Revitalization of Serbian industry: the revitalization of Serbian industry is a prompt response instrument. Its task is to activate the existing technological resources of industry in a short-time period, in 3 to 5 years, and make them functional, predominantly focusing upon quantitative aspects: increase in the 
scope of production and creation of new jobs in manufacturing (parrying to the economies in the region whose industries employ by far a larger number of workers).

The sustainability of this instrument in the conditions of limited financial resources is based on the following elements: 1) the existing industrial infrastructure and production programmes, 2) the existing human resources who were forced into other fields of economy as a result of long years of stagnation and 3) industrial and cultural tradition. The revitalization of large companies and industrial systems will help change the technological basis of Serbian industry to a considerable extent, through an activation of "frozen" technological resources and with minimum investment. Simultaneously, the revitalization of large companies can create a large space for the development of the small and medium-sized company segments in manufacturing whose development and survival were blocked in the past period due to the absence of large industrial systems (large companies as umbrella to small and medium-sized enterprises). In such a context, the companies in the restructuring process and even those undergoing the liquidation procedure, become potentially very important.

STAGE II - Re-engineering of Serbian industry: the re-engineering of industry is an instrument for the reconstruction of the technological basis and technological defragmentation of the production chains of the industry of Serbia through an intensive development and innovation processes in the LMT industrial segment. The implementation of this instrument means an efficient execution of Stage I, namely, the initial impuls of technological revitalization of the Serbian industry. The implementation of this instrument has its incubation phase and also a phase of full operational implementation. The basic goal of this instrument is to improve the productivity and competitiveness of the Serbian industry through investments (quantitative growth) and an intensive technological development (qualitative change) in the LMT sectors. Furthermore, the goal of this instrument is an essential step forward in the product structure generated by the industry in Serbia towards higher-level processing products of higher added value, enriched by a wide range of services as a vital component of modern industrial production. Such changes can create a realistic basis for a long-term sustainable growth in industrial exports, which is one of the key goals of the new strategy and an essentially important need of the economy of Serbia in order that it should efficiently resolve the current problems in the balance of trade and the increasing budget deficit.

In developed economies, innovation policy by a rule focuses upon the high technology area (HT industry), leaving behind the low-technology and medium-technology areas (LMT industry $=\mathrm{LT}+\mathrm{MLT}+\mathrm{MHT})$. Recent research shows that such an approach is wrong, that is, incomplete [33], since the LMT industry has a large space for an effective implementation of varied research and development contents, primarily through the introduction of high technologies (industrial automation, robotics, mechatronics and related technologies derived from a large pool of industrial information and communication technologies) including a wide range of research and development activities in the domain of generic technologies implementation (e.g., biotechnologies in the complex: agriculture - food industry - biotechnologies / food manufacturing technologies / agricultural robotics).

This fact is of great importance in case of the industry in Serbia. Innovation in the LMT sectors may bring about fast and abrupt effects in economic growth, primarily due to the fact that technological innovation can be implemented through extensive processes of modernization of the existing industrial infrastructure and that this is the domain in which the available industrial resources and the technological know-how of equally formal and tacit characters are predominantly concentrated. In a nutshell, the LMT sectors of the Serbian industry in 2008 included $94.9 \%$ of industrial enterprises, employing $93.1 \%$ of workers and earning $92.5 \%$ GDP. Serbia should count this as its comparative advantage, not as a weakness.

Characteristic of the LMT segment is an incremental character of innovation processes as innovation processes focus upon raising productivity, product line differentiation and marketing activity improvement. It is important, however, to stress the fact that these innovation processes are, as a rule, considerably more complex than introducing new technology by purchasing new production equipment and that in many cases innovative activities in the LMT segment include high technology products and processes that spread throughout the entire value chain. A typical example is the implementation of ICT, CNC technology, robotics, optronic technologies, new materials, biotechnologies or latest CAx technologies for engineering design in the development of new products and new production processes. These are technologies with an immense innovation potential and they ensure a rather fast industrial growth (especially in the industry of Serbia which has for over two decades been in a total stagnation and technologically rusty as regards 
development, with a devastated developmental infrastructure). Besides, a diffusion of high technology contents in the LMT segment has an important effect on the development of high technology industries and the $\mathrm{HT}$ segment altogether, although in the concrete case of following such a strategy, the HT segment within STAGE II would be a side activity, out of the central focus.

Implementation of high technology contents in the LMT sector changes its technological basis through the change in the occupational profile of labour force, the change in the company organizational structure and a significant change of the companies' business interaction with the environment, including an increasing need to collaborate with research and development institutions on various innovative programmes. Due to its real needs, the LMT sector can, at a certain moment of its development, generate a strong impuls for the expansion of research and development and educational capacities and thus launch a process of accelerated technological development. Due, again, to their incremental character, the domestic science and education can easily meet such requirements through an evolutional adjustment of their own research and development and educational programmes and/or carefully guided technology transfer process and scientific collaboration within the ERA segment of the European Union [23], as well as through an intensive participation of the domestic science and industrial companies within the strategic programme of the European technology platforms (ETP) [9], [11], [12], [13]. Of special importance here is designing the own programme of national technology platforms as complementary to the ETP programme, through its extension to the national level. The new industrial policy recognizes the National technology platforms of Serbia programme - the NTPS program as one of strategic priorities for a long-term activity in the area of academic and industry environments interaction, with an aim to transform and strengthen the technology basis of the industry in Serbia. The institution deeply engaged in the National Technology Platform of Serbia programme is the Academy of Engineering Sciences of Serbia - AINS (AESS - the programme initiator and coordinator) with its expert resources with a wide range of competences covering the overall area of engineering activities. The National Technology Platform programme functions within an industry-research-investments developmental triangle which is understood as a platform for creating a sound economic system that will function as a national wealth generating machine (Figure 5) transforming money into knowledge, knowledge into innovation, innovation into innovative products, and finally, through innovative products valuation into money again, however, a larger amount of money than that invested into knowledge generation.

Conceptually, the NTPS programme focuses upon three basic goals of technology development and knowledge-based economy / industry building:

1. Creating a formal framework for stakeholders, led by industry, to define development and research priorities, time frames and action plans for a number of strategically important issues of which the development and economic growth of industry, employment, competitiveness and sustainable development are interconnected or dependent on the development of technologies and technological achievements in a medium-term and a long-term plans.

2. Creating a formal framework to ensure an adequate allocation of funds earmarked for research activities to areas highly important for industry, including the overall economic value creating chain and mobilizing social authorities and regulatory bodies on both the national and the regional levels.

3. Identifying technological processes that potentially contribute to satisfying the key social priorities that are of crucial importance for the development of the national economy competitiveness, including:

- Development of new twchnologies in the context of sustainable growth;

- Intensive development and implementation of high and emerging technologies;

- Generating new high technology products and services for mass consumption;

- Renovating, restructuring and revitalization of traditional industry sectors via implementation of the latest technologies and innovations.

Operationally, the NTPS programme can be described as a set of autonomous and interconnected individual technology platforms specialized in a certain industry domain and displaying both national and European dimensions in their manner of work (Figure 6). In the first phase of execution, the NTPS programme includes the establishment of six individual platforms: manufacturing, food, energy, construction, transport and ICT. The listed technology platforms can have a tremendous effect on the technology development in the LMT industrial sectors, primarily through the technology transfer model. 


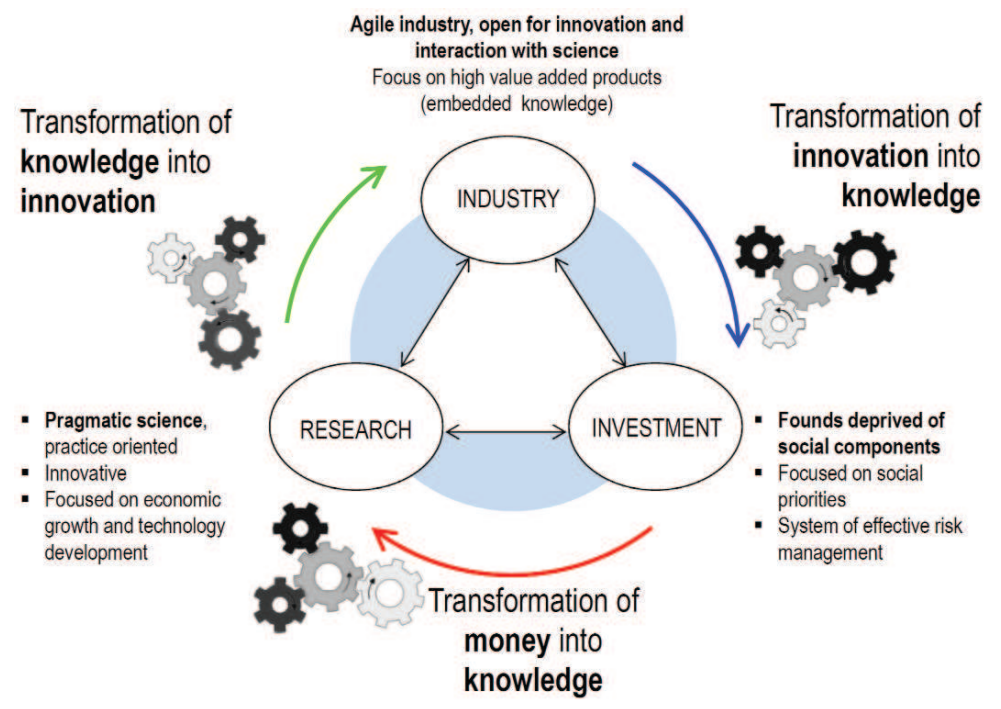

Figure 5: The triangle of knowledge underlying the National Technology Platform of Serbia initiated and operationally conducted by the Academy of Engineering Sciences - AINS.

Serbia has a respectable industrial tradition in the high technology area which is applicable in the LMT sector. This is in the first place the traditionally rooted knowledge in the area of industrial automation that is equally present in the manufacturing practice, in the research and development area and in the area of educational system, including the entire secondary and tertiary levels of education. Curricula should be innovated through a broad Agile industry, open of information and communication technologies, through a multidisciplinary approach (e.g., focusing on mechatronic systems as a key engineering component of a majority of modern products and modern production processes) and a practical work during which practical skills are mastered and focus is placed upon creative problem solving. The notion of creativity should be redefined in the sense of developing skills, not only for creating innovation, but also for the implementation of innovation. Industry increasingly works on a concept of open, free innovation used to introduce radically new contents into the innovation systems of industrial companies through a changed nature of innovation - innovation that does not necessarily emerge within the company, but appears as commodity, something that can be purchased or developed in collaboration with the environment, [29], [30] and [32].

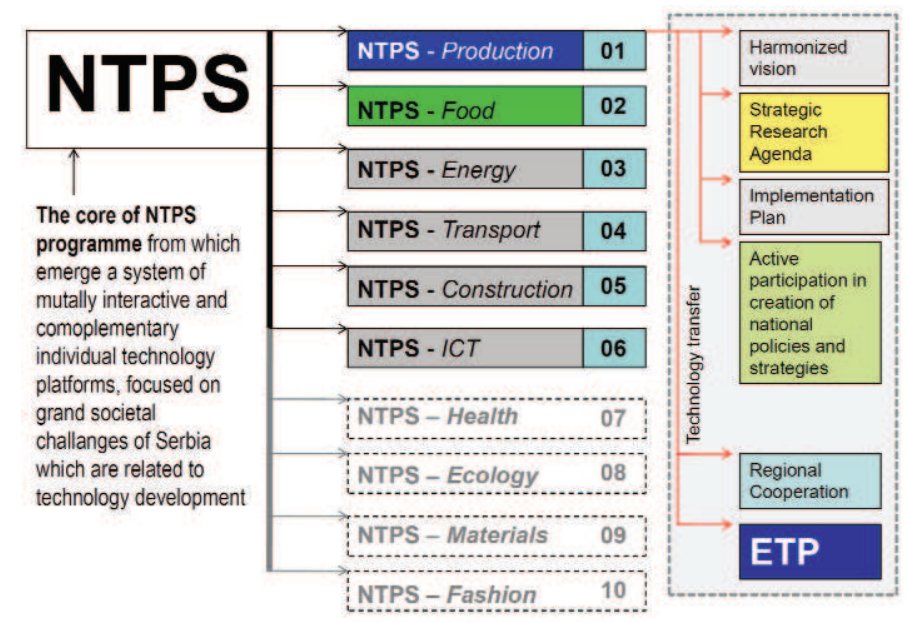

Figure 6: NTPS Programme structure. A set of 10 inter-complementary and functionally integrated individual technology platforms oriented towards key social challenges. 
STAGE III - Development and growth of Serbian industry: The development and growth is an instrument of change of the technology profile of Serbia through building new high technology sectors and innovative potentials and contents growth in an intensive interaction of industry and research and development and educational institutions in the development triangle defined in the NTPS programme. Only a vital industry, one with structural complexity, functional innovation mechanisms and respective investment capacities can be mature enough for a developmental expansion to high technology sectors and newly emerging technologies and industries. The implementation of this instrument assumes that Stage I and Stage II of the Serbian industry technology revitalization and transformation policy have been successfully completed.

The key role in the implementation of this instrument belongs to the National Technology Platform Programme - NTPS, through a cluster / network of individual technology platforms with their visions of technology development and long-term programme brought together in the form of Strategic research agendas in compliance with national human and material resources, cultural tradition, national social priorities and a strong link and full complementarity with a body of European technology platforms. Operationally, the developmental expansion of the industry in Serbia will be defined by the Strategic agendas of the cluster / network of individual technology platforms and prevailing social priorities of the Republic of Serbia for the $2020-2030$ period.

The implementation of the three listed instruments in the revitalization and development of the Serbian industry requires that basic scenarios be defined using a time and functional quantification. To devise a scenario of Serbian industry development for a period from 2011 to 2030, it is important that the development potentials the Serbian industry achieved should be quantified, as this is the context preceding the period of political and economic crisis from 1990 until 2010. This is a period of stable growth and development of industrial production which lasted from 1960 until 1990. The development of industrial production in this period is well described using a linear approximation as a period of industrial production annual growth of $7.8 \%$ and the index of production IP1960 $=16 \%$, as referred to 1990 , namely to IP1990 $=100 \%$.

Furthermore, important for the design of the industrial development scenario are certain reference levels that can be used to characterize the present state of the art and the one to be achieved through the execution of variance scenarios. Reference levels can be production indices achieved in $1970-$ IP1970=42\%, in $1980-\mathrm{IP} 1980=91 \%$ and in $1990-\mathrm{IP} 1990=100 \%$.

Anyway, a close look at the linear model of growth for the period from 1960 till 1990 reveals that the crisis began as early as 1985, when the industrial production growth was recorded to be negative in the five-year period, from 1985 until 1990, with an average value of $-2.77 \%$ annually (Figure 1a).

The starting position for devising variance scenarios of development is the fact that industrial production index for the year 2010 almost equals the 1970 index and that the csope of industrial production in the preceding twenty years practically did not change. The extrapolation of the identified linear approximation of industrial production growth can help assess the scope of industrial production in 2010, when the crisis period was somehow avoided and compare it to the industry performance index in 2010. The graph in Figure 7 shows a difference of $131 \%$ of lost industrial potential! The space between the achieved industrial production index and the linear approximative model shows the overall losses of the Serbian industry and economy in the period of $1990-2010$ economic and political crisis. The qualification of the present state through a comparison to the industrial production index achieved in 1970 is only partly accurate. An entire qualification requires that the dynamic component should be compared as well, and also some other indicators (Figure 1). In 1970 industry was developing fast, with a stable long-term industrial production growth trend of $7.8 \%$ annually. The year 2010 and alnost two preceding decades are characterised by a virtual absence of the dynamic component, namely, by a zero growth trend - the industrial production index displays a stohastic character with random years with either positive or negative values of industrial production indices, always of low absolute intensity. It is for this reason that the losses of the Serbian industry and economy in the $1990-2010$ economic and political crisis are the losses that have to be understood as an enormous erosion of material and intellectual capital as well as an enormous erosion of dynamic, developmental component, resulting in severe social tensions and a general material and spiritual poverty in Serbia.

Starting from the present conditions and taking into account the period preceding it, two margin programmes of satisfying the strategic priorities of Serbian industry recovery are possible to use in the 2010-2030 period: the MAXIMUM Programme and the MINUMUM Programme (Figure 7). 
The MAXIMUM Programme is the upper border scenario through which the industrial production capacity lost in the period of 1990-2010 crisis can be restored almost completely, with a large potential for further growth and development.

The MINIMUM Programme is one of conservative / slow development and follows a linear model od growth. This model is derived by copying the linear approximation of industrial production growth in Serbia achieved in the period 1960 - 1990 (a three decade period of steady growth - the context preceding the crisis). The industrial production arithmetic growth progression coefficient at this period had an average value of $7.8 \%$ annually. With the implementation of such a linear development model the Serbian industry would achieve a growth of $79.5 \%$ in 2020 , in comparison with 1990 , which is significantly lower in comparison with the production index achieved in 1990. The 1990 industrial production index would in this case be achieved as late as 2027, and in 2030 the industrial production index would amount to $111.7 \%$ in comparison with 1990 .

Two basic scenarios of industry development in Serbia are possible if we take into account the above margin development programmes: SCENARIO I - the Recovery scenario and SCENARIO II - the Scenario of permanent stagnation and poverty.

SCENARIO I is a desirable scenario which is conducted within the boundaries of exponential and linear growth of industrial production, namely in the space between the MAXIMUM Programme and the MINIMUM Programme. The realistic path of industry recovery and the amount of permanent losses of the industrial capital of Serbia will in that case be defined by the level of resolve the Government of the Republic of Serbia has in implementing the proposed industrial strategies and policies as well as by the achieved level of mobilization in the society in general.

SCENARIO II is one that is conducted below the line of linear growth, and this is a scenario that still persists in the way of thinking today and in an indecisive industrial policy. It declares itself in favour of industry recovery, however, in reality, it acts towards its essential marginalization through focusing upon the concept of industrial autopoiesis, that is, self-development achieved via the inflow of foreign investments and the absence of an effective coordinating function of the state. Such a scenario is a scenario of a long-term projection of poverty or permanent stagnation with a trajectory of random oscillations of the production index, which is similar to its values in the period 2000 - 2010. This is the Brown motion of the industry development path with a growing dissipation of national resources, loss of jobs, a further technology erosion and rising social tensions. This scenario does not exclude a variant of extremely negative development, namely, an industrial production collapse and an entire devastation of the Serbian economic system (Argentine, Greek, or similar processes).

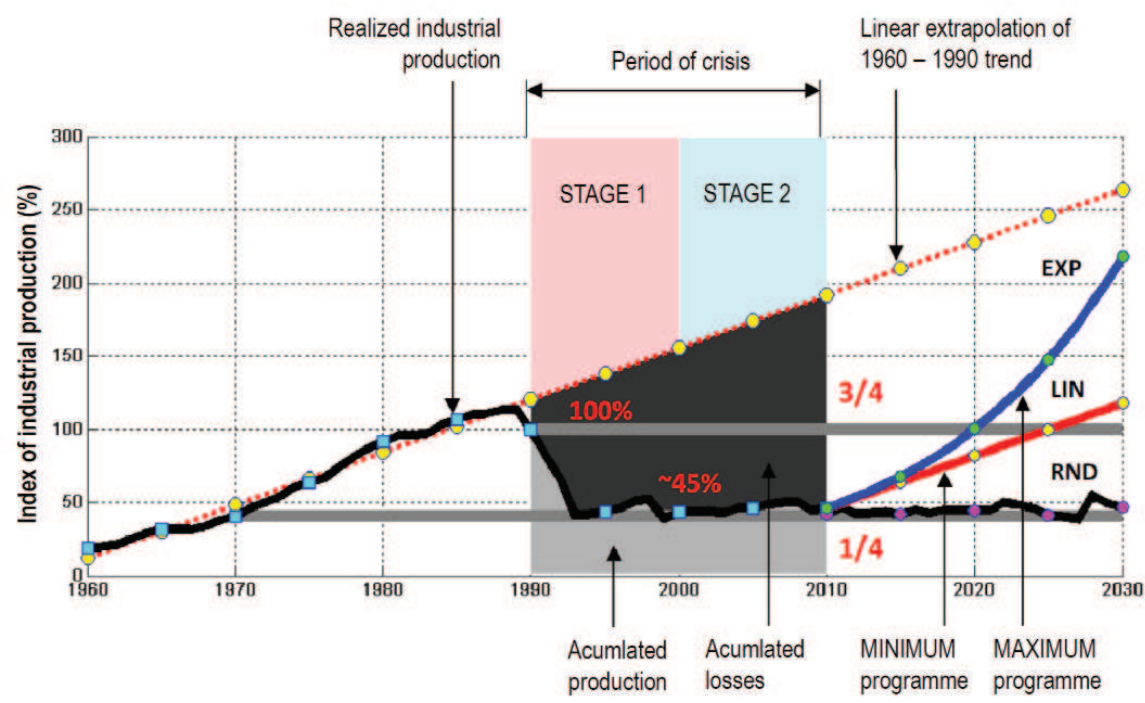

Figure 7: Quantification of time and production frameworks of industrialization process and identification of border lines for the two basic industrialization scenarios 
The above presented facts lead to a conclusion that the border line dividing the presented scenarios is defined by the following quantification of the basic scenarios of industrialization:

A. By 2030 the scope of industrial production should be brought to the pre-crisis level, ensuring a potential for further sustainable growth;

B. In 2030 , the number of industry workers should amount to $\mathbf{7 5 0 . 0 0 0}$, at least $20 \%$ of them with tertiary education;

C. In 2030, the share of industrial production (manufacturing) in GDP generation should amount to $25 \%$.

D. In 2030, the technological profile of industry has a strusture of $\mathbf{3 0}-\mathbf{4 0}-\mathbf{2 0}-10$ (LT - MLT - MHT $\mathrm{HT}$, respectively).

The given quantification framework is simultaneously a qualification border line, the line that divides our future into two alternative possibilities: pessimistic - a permanent weakening and a growing poverty and optimistic - progress with a simultaneous recovering of what was lost in a broader framework of 2 to 5 decades.

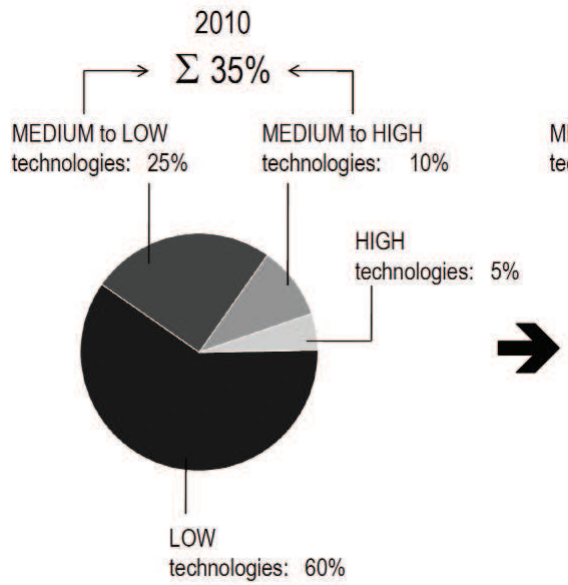

$60-25-10-5$

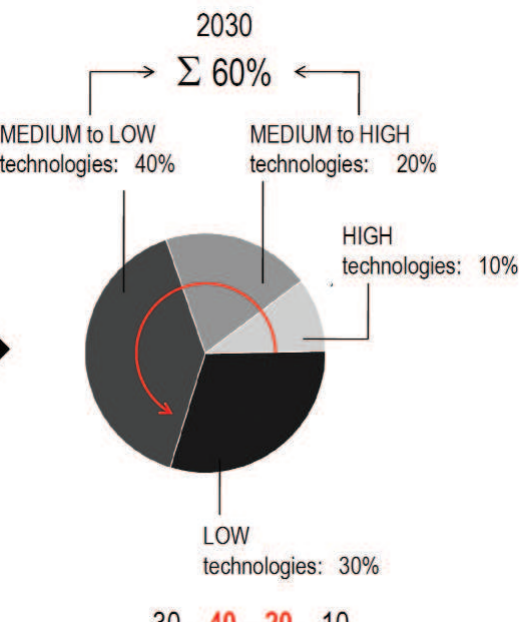

$30-40-20-10$

Figure 8: Transformation of the technology profile of Serbia by 2030 (on the left - the current profile).

The first step in pursuing any active industrial policy or planning the industrial development on realistic basis and with realistically set goals should necessarily be the identification of the present state of the art. It is for this reason that the Academy of Engineering Sciences of Serbia devised the TeMaS Project, namely, the Technology Maps of Serbia, based on a twelvedimensional metric space:

1. Human resources and technological intellectual capital of formal and tacit nature;

2. Infrastructure production resources;

3. Technical and technological structure of product line;

4. Organizational model of production, production processes and production chains;

5. Technological bases in the area of product design, production processes, organizational structures and marketing;

6. Innovation competence;

7. Mechanisms for interaction with business environment;

8. Supply chains and logistics, raw-material and energy bases of production;

9. ICT technology implementation;

10. Ecology - environmental protection;

11. Energy efficient processes;

12. Production system management, quality management mechanisms, productivity and competitiveness management. 
Simultaneously, of crucial importance for launching transformation processes are three trans-sectoral, horizontal programmes:

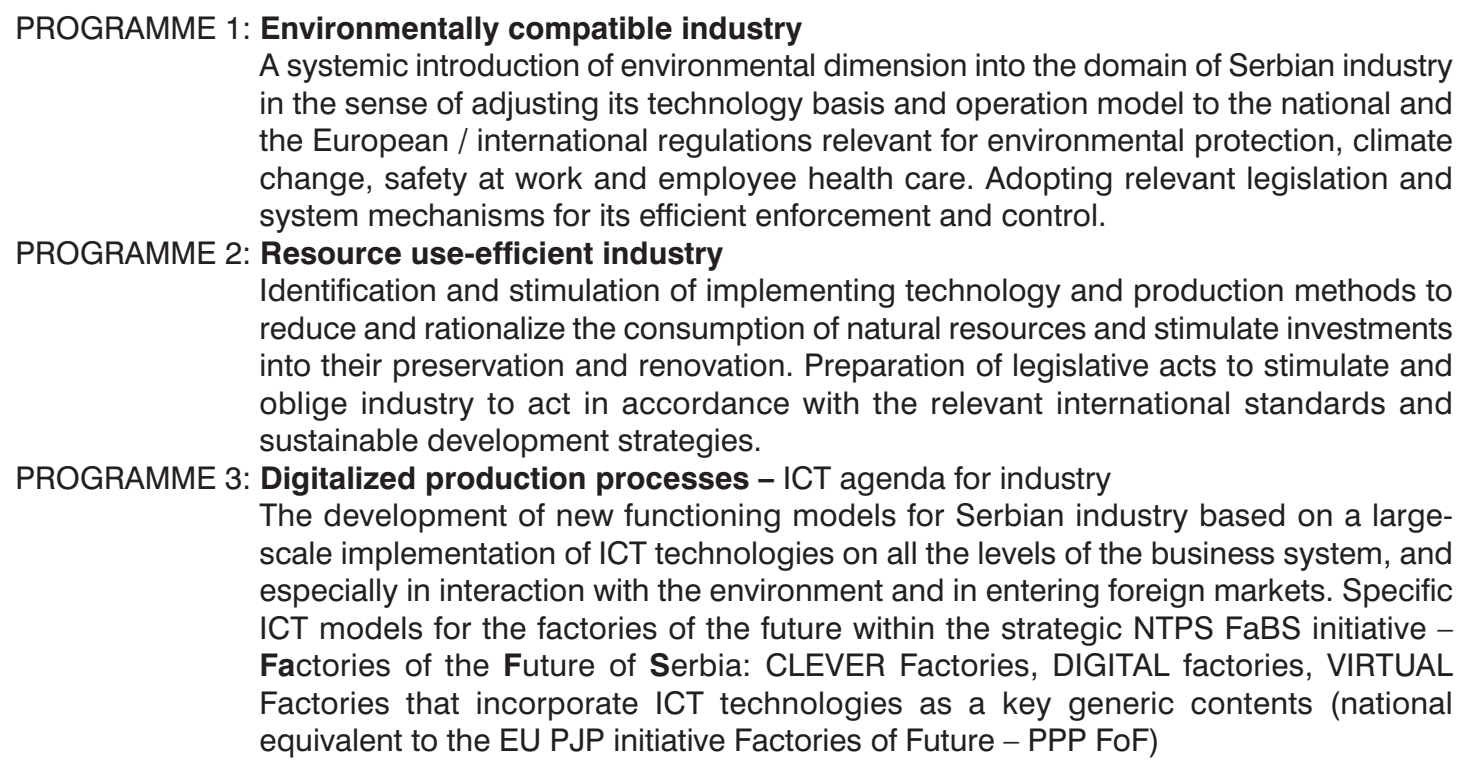

\section{New industry}

Serbian industry transformation in the context of European integration processes, the future context (factories of future), challenges and needs

The process of Europen integrations of Serbia should play an important role in the selection of strategic decisions concerning industry transformation in Serbia. The models Europe implements, regardless of technology and other distances, are far from irrelevant for Serbia. On the contrary, their relevance is paramount since the market competition goes in a single, shared space and technologically weak players are naturally eliminated (globalization is an enemy to ignorance!).

Relevant in the domain of technology development and inclusion of a wider scientific community in the process is the Horizon Project 2020: the EU Framework Programme for Research and Innovation Horizon 2020 - Financial instrument implementing the Innovation Union, a Europe 2020 flagship initiative aimed at securing Europe's global competitiveness.

Its basic framework is the following: Running from 2014 to 2020 with an $€ 80$ billion budget, the EU's new programme for research and innovation is part of the drive to create new growth and jobs in Europe.

- EXCELLENT SCIENCE: Strengthen the EU'S position in science with a dedicated budget of $€ 24.598$ million.

- COMPETITIVE INDUSTRIES: Industrial leadership in innovation $€ 17.938$ million. This includes major investment in key technologies, greater access to capital and support for SMEs.

- BETTER SOCIETY: Provide $€ 31.748$ million to help address major concerns shared by all Europeans (climate change, sustainable transport and mobility, renewable energy, food safety and security, ageing population).

Prioritizing in this manner, the European Commission clearly stresses the importance of industry for the future of Europe. The Programme has only three priorities, one of them explicitely related to the technology development in the context of strengthening the European industry competitiveness and the budget earmarked to achieve these goals amounts to $€ 18$ billion. 
European Economic Recovery Plan 2010-2013

Public Private Partnerships in Research Activities

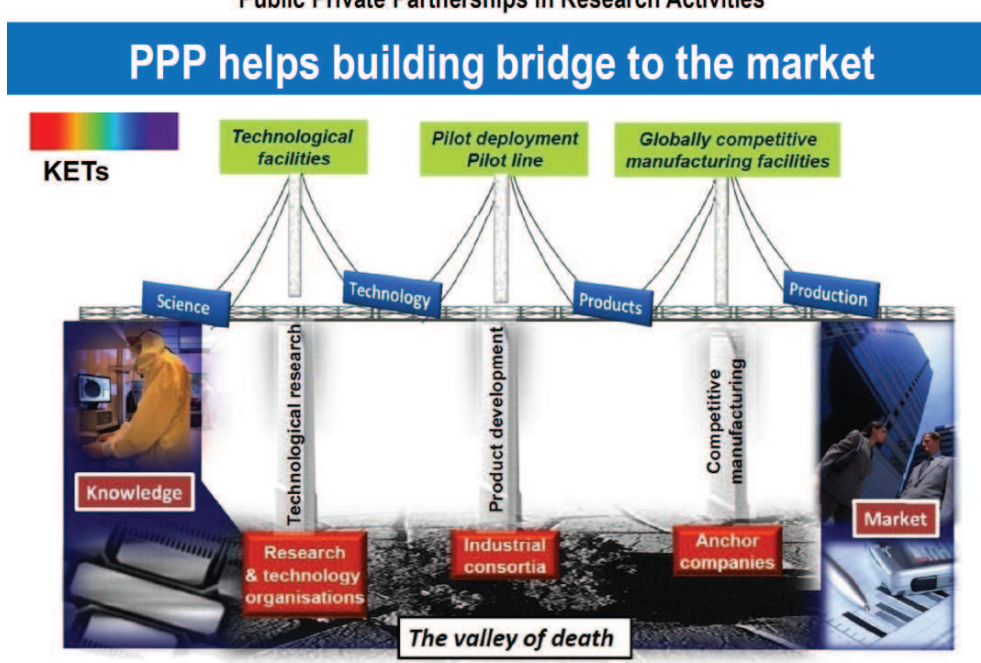

Figure 9: Programmes of public and private partnerships in the European Union to bridge "the Death valley" of European economy through a strategic framework for building three tiers to pragmatize European science and make it function towards strengthening global competitiveness of European economy, especially manufacturing [15].

Simultaneously, Europe further elaborates and implements the instruments of public and private partnership built in the context of Europe's response to the first hit of the 2008 economic crisis and placed into the context of the European Economic Recovery Plan 2010-2013, [8]. The essence is in what Europe poetically titles "The Death Valley", thus highlighting the dramatically severe problems arising from the absence of market implementation of research results attained in the domain of science (Figure 9). It is in this context that Europe formulated an adequate strategy to bridge this gap and it is based on three tiers: 1) Orientation of science towards technological research, that is, transfer of scientific results obtained during basic research to the domains of technology and engineering, 2) Directing the research in the technology domain towards practical demonstration of results and building pilot installations within the selected mixed consortia from the domain of research and development institutions and manugacturing companies and 3) Focusing on the construction of new generation factories that will be capable of adopting new technological solutions and new products with a high level of added value and built-in knowledge.

Technology forecasting for Next Generation Manufacturing (2030) Key enabling technologies and manufacturing challenges

Volume Production Back to Europe

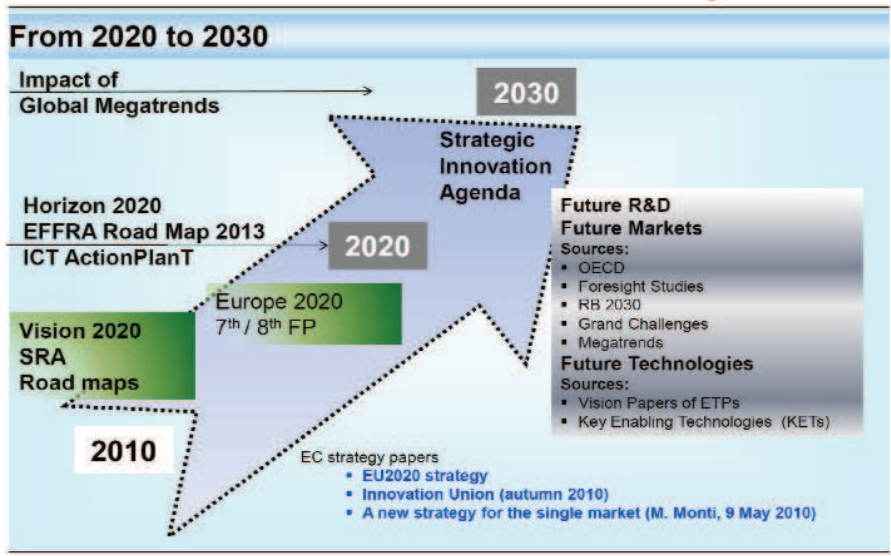

Figure 10: Strategic programme framework until 2030 for the construction of new generation production systems for the purpose of transforming the European production base towards a mass return of industrial production from the countries with inexpensive workforce to the European soil again [25]. 
An even wider context of above listed activities that is partly set into the European technology platforms, and especially in the Individual Technology Platform for the production technologies domain - ManuFUTURE: The Future Manufacturing Technologies of Europe [23], [24], [53], where, in the timeline stretching up to 2030, a number of parallel programmes are conducted with a single goal - a massive return of industrial production to the European soil, however, in the manner that will be competitive not only in quality, but also in price in comparison with the present situation of industrial production dislovated to the countries with cheap workforce. These programmes will be supplied by a new generation of manufacturing technologies based on new generation robots, on mechatronics and other ICT based manufacturing technologies. The production bases of the industry of future will be essentially different in comparison with the today's stereotypes and this is the future that cannot be avoided in the globalized world.

In view of the above presented it is clear that the industry of Serbia, after it has been restored and brought into a functional condition, has to undergo transformation and bridge a two decade long gap to reengineer its technological basis and thus create a sound basis to achieve the necessary competitiveness, measured globally. The transformation process should be carried out through an imperative action of two regulatory instruments: complementarity and compatibility of the industry of Serbia with the European economic domain. At first sight, these are two antagonistic, conflicting instruments, mutually exclusive. In reality, these instruments ensure an accurate guidance and convergence of transformation processes that tend to be completed successfully, that is, to enable a new, transformed Serbian industry with its recognisable, respective and sustainable position in the European economic domain, and in a long -term period.

Complementarity is an instrument whose function is oriented towards finding a spot in the single European market in which the Serbian industry will ensure its long-term and sustainable economic and technological existence, primarily through the competitiveness framework that will be based on the national comparative advantages that stem from: 1) national cultural heritage, 2) national industry tradition, 3) geographical and regional specificities and 4) available infrastructure, natural and especially human resources.

The complementarity instrument can be illustrated through the agricultural sector present in many a document as a strategic advantage and a development opportunity of Serbia. Agriculture in itself cannot work by itself as an isolated agrocomplex has no potentials to ensure a modern living standard in the areas with the population density present in Serbia or in the European Union (the emergence of industry organizational model of material production pushed the agricultural economy back to the past by a more potent concept of industrial economy). It is for this reason that agrocomplex should be placed in another context that is vital for industrial production and these are high value added products. Concretely, instead of focusing upon agrocomplex as an isolated economy sector, it is necessary to focus on food production. In the context of food production, agrocomplex is but one component in a long technology chain of high value product creation. Here the product means material goods created through manufacture with additional services as intangible products directly or indirectly connected with industrial production processes. This approach enables the agrocomplex to achieve a significantly more valuable position, a position of a quality generator of a raw-material basis for food industry where the primary agrricultural produce undergo further industrial processing and absorbs knowledge in order to gain new quality that considerably increases its initial value. Such an approach simultaneously enables the development and growth of other industry segments that are indirectly connected with food producing industry, such as, for example, the agricultural mechanization industry segment, in a state of total stagnation at present. It is in this segment that Serbia has a long industry tradition, a respective industry infrastructure and a recognizable market image. In such a context, the agrocomplex assumes the role of an initiator; it becomes a generic basis of economic development rather than a consumer of budgetary funds that more or less subsidize the agricultural activity altogether. The food producing industry in which technology plays the key role with knowledge and skill as its key components, opens the doors for Serbia to valuate its competitive advantages in a significantly better manner. These are the advantages that in this concrete example stem from its specific geographical position and, consequently, favourable natural predispositions for a massive agrocomplex development. Such an approach is practically a generic model that is the basis of the mechanism controlling the functioning of the complementarity instruments for the transformation of the Serbian industry within its European integration processes.

Compatibility is an instrument used to ensure the adjustment of the Serbian industry to the industry production standards within the economic system of the European Union (this automatically implies global framework, too). Here, compatibility should be achieved as regards four aspects: 
I. Organizational structures and business models of the production system;

II. Sustainable development framework and implications on the production system;

III. Social challenges and implications for the production system observing own national specificities;

IV. Technology basis and the technology development system as basis of the European Union industry.

These elements are further elaborated with reference to strategic frameworks defined by the relevant EU documents, studies and work communications, predominantly focusing upon the technological aspects of the production system.

1. Organizational structures and business models of the production system: Organizational structures of production systems change continually [20]. The paradigm of mass production established in the first decade of the twentieth century through 1) Ford's production line form, 2) tolerance and parts substitution concept and 3) labour division into manufacturing operations has been replaced in 1990s by a paradigm of mass customization of products [28], [31]. The essence of this new production paradigm is shown in Figure 11 and it primarily lies in individualism, i.e., in mass personalization of production through an extreme variance of products.
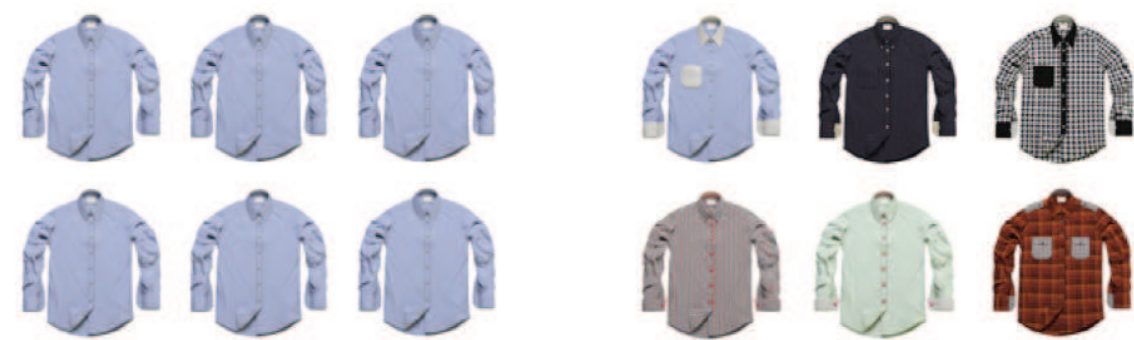

MASS PRODUCTION

MASS CUSTOMIZATION

Figure 11: Concept of new mass customization production paradigm - extreme variance of products requires an extremely flexible production equipment.

The mass customization paradigm has had dramatic effects upon all the elements of the production system. Generally, the core of this paradigm is that industry is faced with the need for individual, that is, multivariant production that was present during the times of handicraft production, however, with the attributes of productivity and production costs achieved by the mass production concept. This seemingly contradictory requirement, an oximoron in itself, can be solved via an extensive implementation of the modularity concept as well as via the introduction of the cognitive dimension into the production technologies, namely, through designing intelligent machinery, robots and production lines for the purpose of ensuring an extreme flexibility, by all its attributes close to the flexibility of manual production. Although the artificial intelligence concept has for long been known in engineering, it is still far from being practically implemented, so that the new production paradigm of customized production has created a large space for launching accelerated research activities in the development of this radically new and highly valuable technology. Organizationally, the new paradigm of customized production essentially changes the business model of the production system transforming its traditional structure: design - production - sales into an inverted structure: sales - design - production, which then has further substantial consequences for the overall technology chain of value creation. The primary drivers of this change in the production paradigm of industry are the market and the fact that over a time, technological development and productivity growth in a large number of global industry sectors have made the production capacities larger than the market capacity is (e.g., in the automotive industry), so that the problem of approaching customers has become more delicate than technical and technological problems accompanying production processes.

Simultaneously, the customer too joins the production process through the framework of the production paradigm of mass customization in that they use the Internet technology. An example of this approach devised by the Adidas company is presented in Figure 12. Among other things, Adidas have found a technological solution to this situation through a wide implementation of the modularity concept, however, this concept here does not include only the product, but also the production processes, which has serious implications for both the production system as a whole and the production technologies on the basis of which it was created. 
The pressure of global climate change and the interaction of industry and environment becomes increasingly pronounced, accordingly, there are predictions that the new paradigm of customized production in the first half of the 21 st century (most likely in the thirties of the century, perhaps a decade earlier) will be replaced by a new production paradigm, that of sustainable production in which the interaction between production processes and the environment will become dominant in comparison with the currently prevailing interaction between production processes and the market. It is also possible that the context enforced by the production paradigm of mass customization will simply be amended by new limiting factors of human ecosystem sustainability.

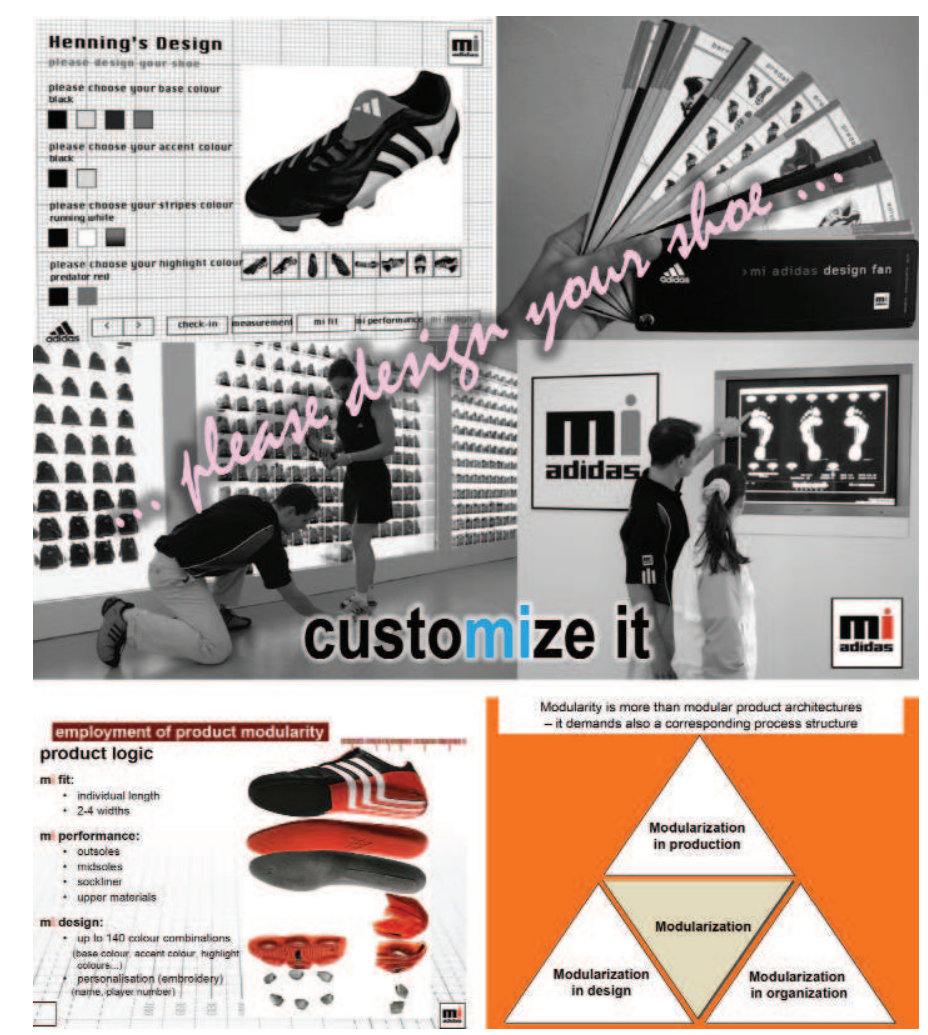

Figure 12: Modularization as one engineering response to the requirements of new production paradigm of mass customization, an example of the Adidas company

Organizational structures and business models of the production system are largely affected by globalization. Locally concentrated production structures are gradually replaced by both locally dislocated and globally dislocated production structures, ones that are changeable in time and that possess an inherent dimension of fast and deep reorganization as response to stimuli coming from the market (not only from customers, but also from material, infrastructure and human resources, as well as from the legislative context connected to the produstion process). This changes the traditional organizational form of the factory, replacing it by a new, flexible form, a virtual factory in which the business dimension dominates the infrastructure and human resources.

The answer to the above listed and many other organizational and business aspects can be found in a large number of strategic documents issued by the European Commission and specialized work groups. Especially important here is the Factories of Future programme (FoF programme) [16] initiated by the European Technology Platform ManuFuture [23], [24], [53], as a response to the 2008 economic crisis and, related to it, the reactions of the European Commission in initiating and inciting a broad range of activities of both public and private partnership whose realization engaged both industry and the scientific and research community of the single research area of Europe. For the purpose of operationalization of the FoF programme an adequate institution was established in the form of association, EFFRA - the European Factories of the Future Research Association, located in Brussels and responsible for the operational execution of the FoF programme. In this context it generates the documents relevant for the development of the European in- 
dustry, research and education areas. The FoF programme is not a novelty for Serbia [14]. A similar programme was developed in Serbia in 1980s, in the period preceding the crisis in the 1990. It was a highly advanced programme at the time, not only within the national boundaries, but much wider. This programme should be renewed and set into a new context, and the starting point should be experience from that past period, the EU ManuFuture FoF initiative and parallel programmes at the national level, as is, for example, the Italian La Fabbrica del Futuro programme. In the context of organizational structures and business models set into the context of new approaches in the value creation mechanisms in case of factories for future (factory, namely, the production system as the system that transforms material, energy and information into a newly created value where value adding is perceived as the basic function of the production system), the following transformation frameworks are listed for the European industry:

1. Transformation of customized production into personalized production (including manufacturing with a unit scope of series and the production of unique products on competitive basis);

2. Extension of the virtual factory model from delocated to globalized;

3. Transformation of production systems based on the 'product/service' concept - product based production into the production systems based on the 'services through product' - solution based production:

4. Transformation of user-geared product into the product geared to customer satisfaction;

5. Virtualization and digitalization of the link between production and business models.

Especially important is the attitude that innovation should in itself become a business model and continually affect business processes [32]. Collaborative business models between companies belonging to different industry sectors carry a large potential so models related to these should be researched into and implemented in practice.

II Sustainable development framework and its implications for the production system: Relevant for this aspect of transformation of the Serbian industry on its path towards European integrations is the strategic document 2020 by 2020 - Europe's Climate Change Opportunity [6], [7], and operational documents derived from it, such as the Green paper for industry. These are rather rigid and binding structures, enforced on the European industry for the purpose of responding to the challenge of global warming, lack of raw-material resources, lack of power resources and environmental degradation [10]. In addition to highly strict limitations, the priorities of the sustainable development framework may be a welcome developmental opportunity for the industry of Serbia. Programmes related to renewable energy carry a large economic potential (here, we must not forget Rifkin's vision of the third industrial revolution and five tiers on which it lies [27]). Similar is the problem of energy efficiency. Different aspects of sustainable development can be part of innovated educational programmes for new generations of engineers. In the general framework of energy and the regime of its use (smart grids) which is a global challenge of an extremely large scope, Serbia has to adjust its power supply framework to its specific features. Serbia is a net importer of energy and power supply has to be brought into the context of an industrial development enabler in the first phase; later, through the transition process of adopting renewable energy sources (bio-mass energy, solar energy, wind energy, geothermal energy, ...), the power supply industry has to be brought into the production context and thus achieve an active participation of domestic industry through the development and production of specific equipment for the new energy regime, rather than import these types of energy and carry on their passive implementation within the national framework.

III Big social challenges and their implications for the production system: The primary dimension of technology is certainly a technical one, however, it has another, hidden at first sight, but equally important, social dimension. Historically, the social dimension of technology is dominant, while its technical dimension helps the social dimension come to being. The essence of this dualism is that technology has a potential to change the living context in which it exists and in which it develops/evolves, through its own evolution process. The living context is understood as a four-dimensional space consisting of: nature, economy, society and technology [20].

The key social challenges, or social megatrends, as they are often termed in relevant documents, affect the development of production system and the social role of industry to a large extent [10]. In this context, the following societal challenges / megatrends are relevant (relevance lies in the thesis that societal challenge which basicaly depends on technology may be an opportunity for business, primarilly in the domain of material production): 


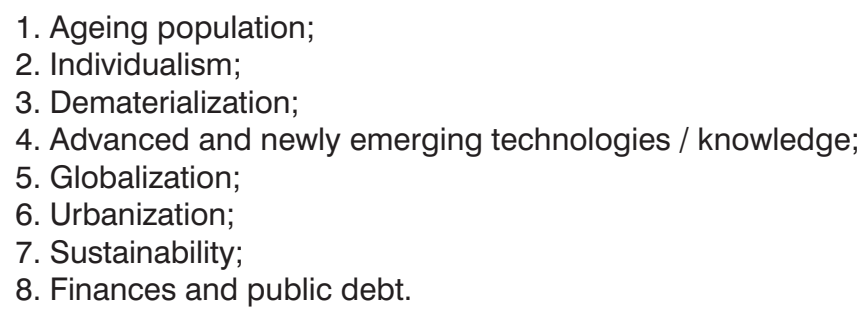

Under the influence of megatrends, the industrial sectors necessarily undergo important structural changes. Looking from this perspective, the changes in the industrial system should be managed, that is, directed in such a manner that the focus should shift from technology as a driver of change to the condition in which the drivers are market needs and social megatrends that trace the path of technology evolution and hence the evolution of the industry system in general. This transformation of the production system will be global in character and Serbian industry will have to face it.

A complex space of industrial system sustainability is defined through three basic components: environmental sustainability, economic sustainability and social sustainability [22]. The above listed sustainability components are further explained in elementary formats:

1. The industrial system sustainability as related to the environment, through reduction of resource consumption and reduced waste production (environmental sustainability):

- Reduction in energy consumption with an increased consumption in the domain of renewable sources;

- Optimization of use of materials and equipment in their final phase of lifecycle through: o Material restoring and recycling;

o Innovative changed use of products and equipment;

- Coevolution of the products - processes - production system with minimum demand for new resources;

- Generation of almost zero emission of greenhouse gases and other waste in production processes;

- Production based on environmentally neutral materials.

2. Industrial system sustainability as related to the human aspects through a synergy of human skills and technology (social sustainability):

- Care and responsibility for employees and citizens within internal and external supply chains in the production system;

- Creation of safe and attractive jobs;

- Increase in human contribution and satisfaction within the production system.

The industrial environment has to be adjusted to man through an adequate milieu and safety concerning his physical and mental health. In the transition processes these issues have been left out of the social context, even out of full control in some cases, which creates serious social problems. Serbia does not need dirty technologies and production systems based on technological solutions that inherently harm the worker's health (worker as expendable resource!!!). Public awareness about this has to be raised and adequate legislature and new programmes in education will have to to create the effects of a barrier that will ensure the sustainability of the industry system as related to human aspects.

In the stable conditions of industry development as exist in the European industry domain, the problems of interaction between man and technology become highly important for the development of industry and factories of future. An integration of man as a biological system and the machine as an artificial technical system is a delicate engineering task which becomes increasingly more complex over time, as the complexity of industrial equipment increases. In the framework of the new paradigm of production systems man will encounter machines whose intellingence and autonomy increase progressively, with the tendency of man being completely left out of the production process. Such a situation creates a radically new environment for man, for the worker who handles equipment and for the design engineer equally. Nevertheless, regardless of the efforts made in this domain, the development of intelligent production systems is evolutionary in nature, due to evident technical limitations, that is, lack of knowledge needed to create entirely autonomous production equipment, machines and pro- 
duction processes. Thus, when we talk of intelligent systems, we mean the hybrid system, one that necessarily has man in its structure, however, it is the man who accomplishes considerably more complex tasks including the process of thinking, while routine and physical work is left to be completed by the technical components of the system (computer-run machines, robots and the like). In any case, in the course of evolutionary process of intelligent production system creation, the conventional interaction between man and the machine will gradually be replaced by a collaborative interaction and team work, and in such a technological entity, man and the machine will share the same task and the same workspace, without physical barriers. The key engineering challenge in hybrid systems is to achieve an optimum / balanced integration of human knowledge and skills into the technical part of the production system, focusing on the compromise between physical and cognitive aspects of the system as a whole, as well as of its parts.

3. Economic sustainability of the production system through the interaction between quality and price-effective productivity

Economic sustainability is the key element in achieving an overall sustainability of the production system. Sustainability in relation to the environment (ecological sustainability) and sustainability in relation to social aspects (social sustainability) can be satisfied only on condition the production system has a competitiveness dimension, thereby it can achieve the market valuation of its activities and thus earn the necessary finances to adequately remunerate employees and invest into production and a further development of the business system. Analyses of the economic area of the European Union show that every job in industry brings with it two additional jobs in the technologically high quality service sector. Hence the economic sustainability of the production system is of key importance for the sustainability of the overall economic system and especially for employment rate growth, and this is one of the most important social problems facing the economy of Serbia. There is no real employment growth without industry!

Economic sustainability of the production system is integrated with organizational and technology aspects. In this context, the Serbian industry transformation process will find it useful to implement models already elaborated in the European Union to solve the problems of this kind. The following theses can be pointed out and they are simultaneously research challenges:

- Reconfigurable and adaptive technology systems and factories, with inherent dimensions of evolutionary adjusting to prompt changes in the production programme, prompt response to market needs, and primarily, ability to achieve economically competitive production in the conditions of small and very small series (including unit and unique item production). In this sense, new technologies and new organizational models are necessary to increase the production system capability of effectively managing an extremely diversified production. Already nowadays, some companies in the European industry, for example in the automotive industry sector, operate with thousands variants of products simultaneously, and in extreme cases the producer does not even have a standard, namely, catalogue model of the product, but rather configures the product of a certain class in accordance with the requirements of a concrete customer. This trend is bound to develop further and soon become dominant in a majority of industry sectors. The paradigm of mass customization essentially changes the production system in all its dimensions.

- Production of complex microelectromechanic products. A large number of commodities falls into this class with a tendency of further miniaturization for the purpose of achieving economic sustainability of production and competitiveness in this area on a global level. This class of products will be of interest to the industry of Serbia in the third phase of its transformation according to the proposed development model - developmental expansion phase.

- The trend of product size reduction and miniaturization (dematerialization) with the use of new materials will set very serious tasks before the industry; the industry then will have to find economically sustainable solutions for the domain of micro-mezo-nano production technologies and systems. Miniaturization imposes new production technologies, non-lithographic technological frameworks for the purpose of resolving specific problems in the micro-world where precision is conditioned by the anisotropic structure of materials (tolerance of the crystal lattice ratio), and in passing from the domain of normal proportions into the micro or nano domain, many physical phenomena change 
their nature (gravitation in micro and nano domains becomes negligible and molecular forces become dominant, and so, for example, picking up pieces by microrobots is technologically trivial, while releasing pieces becomes a rather delicate task due to the dominant action of van der Waals forces).

- Economic sustainability in the domain of high performance manufacturing systems, systems that approach the zero degree of manufacturing error in an asymptotic way, with a simultaneous demand for high energy efficiency.

Economic sustainability of the manufacturing system necessarily leads to an optimum implementation of a broad range of new technologies and technology enablers, particularly ICT, robotics, mechatronics and then advanced technologies derived from them, including the implementation of intelligent sensor systems and an appropriate software and computer management system that will ensure the functions of predictable maintenance and tracking of process parametres relevant for the quality of products in real time and the response to their deviations, also in real time. These are highly complex engineering tasks, and the applicability of this technology set involves LMT industry sectors as well, which is relevant from the aspect of realization of a new industrial policy of Serbia. It is this high technology set that must be adequately covered by the strategy of education of new technology elite for a new industry, in the area covering technical specializations in the secondary and tertiary levels of education.

IV New technological bases of manufacturing system: Important for new technological bases of manufacturing systems, perceived in the European and global conditions, are the so-called key generic technologies (Key Enabling Technologies - KETS) and new manufacturing technologies (Advanced Manufacturing Technologies - AMS) [14], [15].

The key enabling technologies are the technologies generic in nature, with a high potential for radical changes of the living context. These are technological discontinuities that bring about abrupt technical progress with a crucial effect upon the industrial and economic systems in general. In the past, those were the inventions such as steam engine, electricity, or semiconductor electronics, which later grew to become technologies that still, after long decades, retain their clear civilisation impact. Similarly, the key enabling technologies emerge at the present time or will emerge in the future.

From the point of view of technology development, a common characteristics of key enabling technologies is the high demand for research and development activities, a need for large capital investments in all the phases of their development, the multidisciplinarity that covers a broad technical and technological area, large time spans in the devlopment process, a non-linear integration with newly emerged technologies that are generated from them through a diversification process, and finally, a high innovative potential for creating new (more complex) products or new manufacturing processes.

In their mature phase of economic commercialization the key enabling technologies largely affect the economic system through: 1) important changes in the overall industrial system and an emergence or a significant growth of certain industry sectors and 2) development of new markets for new products and services that are derived from them. Within the European Union, the European Commission defined a list of five key enabling technologies of strategic importance for manufacturing technologies: nanotechnology, industrial biotechnology, new materials, micro and nanoelectronics (including semiconductors) and photonics. Europe also recognized the fact that key enabling technology cannot be practically (in the market) valuated unless the sixth component is present - new manufacturing technologies. The key enabling technologies are explicitely listed in the amended industrial policy, as a component of the first strategic tier of European industry development until 2020 (The Six Priority Action Lines) [26].

Given the objective state of the art in the industry domain of Serbia, new manufacturing technologies - AMS are considerably more important. New manufacturing technologies are those with the potential to significantly improve productivity, reduce costs, reduce consumption of material or reduce the effects on the environment, improve the quality or enable other contributions that significantly improve the manufacturing system performance. Contrary to generic technologies that are confined to one technological subarea, new manufacturing technologies are basically a combination of different technologies that allow for a concrete contribution to the overall manufacturing system of a national economy, through their broad applicability in practice. 
New manufacturing technologies include industrial robotics, industrial automation, mechatronics, ICT set of applicative (the design domain and the manufacturing processes management domain) technologies for industry (CNC, CIM, Cax and the like).

A prominent quality of new technologies is that of evolution [20]; integrated with generic technologies they can achieve abrupt changes in the form of technological discontinuity [21]. Similarly, the process of evolutionary development of new manufacturing technologies includes both technological divergence processes and technological convergence processes, which brings about an intensive diversification of new manufacturing technologies. New manufacturing technologies make a major effect upon the industry system competitiveness.

The development of new technologies and their implementation in industry are always connected with a large number of research and development activities, whereas human resources are generated within the area of technical training, especially engineering. Of special importance for the Serbian industry here are information technologies, industrial automation, mechatronic systems, robotics, flexible / intelligent manufacturing systems and Cax methods of engineering design for production. Naturally, such an attitude does not exclude a broad range of conventional technologies that are very important for Serbia and whose abandonment would annihilate the contribution of new manufacturing technologies. This attitude only points to the directions in which it is necessary that new knowledge, theoretical and applicative, equally should be acquired.

1. ICT for manufacturing systems:

The basic challenges manufacturing companies encounter are related to an accelerated growth of the complexity of their manufacturing processes and supply chains, price pressures, growth in customer expectations concerning quality and varety of products, as well as response of the manufacturing system to new market demand. Modern ICT technologies in such a context provide for a more efficient manufacturing process management and a more efficient interaction with the environment. The FoF initiative and the documents of the FP7 programme, in the part referring to information and communication technologies [25], define three basic programmes related to manufacturing systems:

- Smart Factory Programme (Smart Factories) - agile manufacturing and customization, including automated management of manufacturing processes, planning, simulation and optimization, robotics and sustainable development tools;

- Virtual Factory Programme (Virtual Factories) - new value creation within globally networked business doing, including global supply chain management, global management of product-service interaction and management of distributed production resources and production entities;

- Digital Factory Programme (Digital Factories) - better understanding and design of manufacturing processes and manufacturing systems for a more effective product life cycle management, including simulation, modelling and other ICT-based techniques that cover the entire product life cycle, from the concept, through manufacturing, to maintenance and disassembling / recycling.

2. ICT, industrial automation, robotics, mechatronic technologies and cognitive systems

3. Modern manufacturing systems are founded on a cybernetic concept; these are mechatronic systems characterised by a symbiotic coupling of the mechanical system, sensorics (perception), electronics / pneumatics / hydraulics (actuation) and management / software. New directions of development focus upon cognitive aspects of mechatronic systems in order to ensure the necessary autonomous activity in an insufficiently structured environment of a modern manufacturing system. The European Commission earmarked $€ 536$ million to be spent over a five-year period 2007-2012 only for research in the area of cognitive robotics with an aim to bring the European robotics into a globally leading position, recognizing robotics, especially the cognitive aspects of robotics, as the key component in the development of manufacturing technologies. Cognitive robotics means the creation of a new generation of industrial robots, that will, through an appropriate sensory system and new approaches in the processing of sensory information, become aware of their environment, of changes in this environment and on the basis of that be able to act autonomously in a much broader range of situations than in case of conventional programming. Included here is also a collaborative and/or team form of interaction with the man, sharing the common work space and a common task, with no physical barriers. Thus formulated industrial robot systems of new generation are actually industrial humanoids specialized in 
work in an industrial milieu and in accomplishing industrial work tasks in collaboration with the humans. One example of such an industrial humanoid developed within the EU FP7 project ROSETTA, funded by $€ 10$ million, is presented in Figure 13. The key contents in this set of ICT manufacturing technologies are mobility, communicativeness and intelligence. The following areas have substantially contributed to the development of manufacturing technologies: 1) Technology of digital managerial systems, including cnc technology, 2) Technology of visual and physical man-machine interface, 3) Navigation and perception technologies, 4) Technologies for trackning and diagnostics, 5) New technologies of supporting structures that enable reconfigurability of machines and manufacturing systems, 6) Technology of actuation and locomotive systems, 7) Technology of energy systems, including energy accumulation systems, 8) Micro-electromechanical systems, integrated (embedded) electromechanic systems and mobile communications for industrial application.

Speaking of development, the interaction of ICT and industry generates an endless area for innovation and an opportunity for Serbia to use the coupling of industry, research and education and make an important technological step in industry, primarily working in the LMT sector. The National Technology Platform Programme of Serbia - NTPS programme is a respective framework for modelling this process through an inherent coupling of science and engineering, and an inherent integration with the European research and industry domain, based on the formal framework of the European Technology Platforms - ETP.

The above listed four aspects of transformation processes of the industry system are highly relevant for Serbia as they present the platform for achieving the technological and business compatibility of Serbian new industry with the industry of Europe and, simultaneously, with the global standards of manufacturing for the 21 st century. The European integration processes in this context have high potentials since they create preconditions for the establishment of an intensive process of technology and technological knowledge transfer. This process requires Serbia to be open, in the same manner as it was open in 1850s when it build its first factory (the Kragujevac gun factory, 1853) and thus commenced the process of industrialization, namely, the process of transformation from an agricultural to an industrial economy. At the moment Serbia does not dispose of effective and systemically managed technology transfer instruments either in the vertical plane (academic environment - industry) or in the horizontal plane (industry-industry), equally.

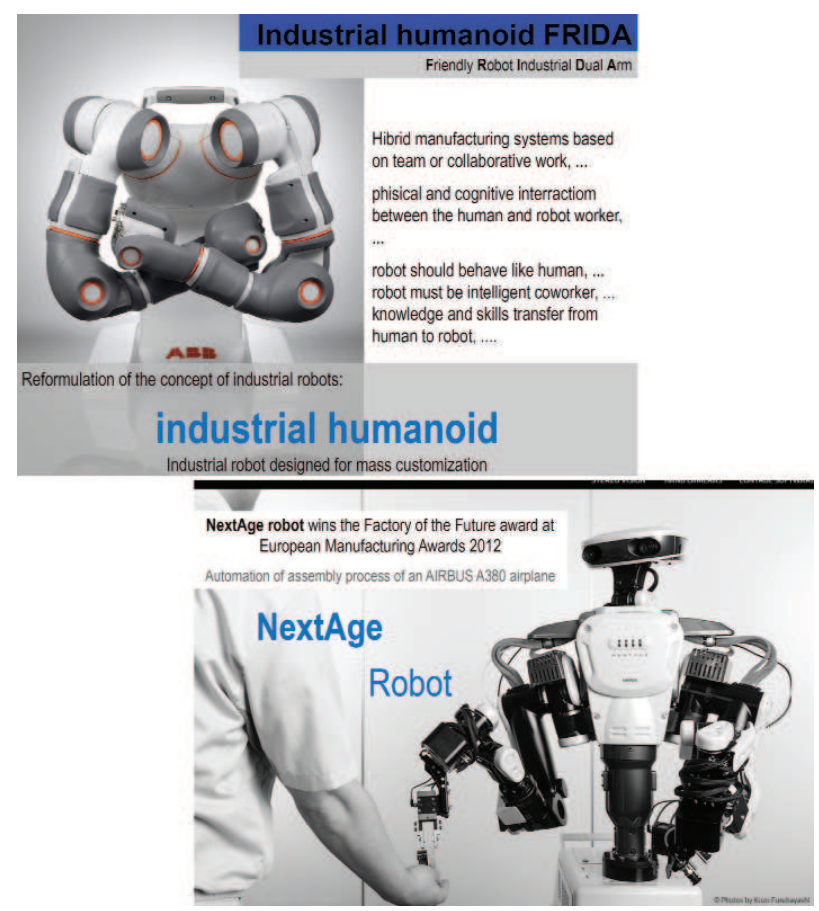

Figure 13: Industrial humanoid FRIDA developed as a robot concept for a new generation of hybrid

manufacturing systems based on extensive physical and cognitive man-robot interaction (European FP7 project ROSETTA, with a fund of $€ 10$ Mio). Down, on the right, the Next Age robot, announced as the robot of 2012 in Europe (used in practice in assembling the AIRBUS A380 aircraft) 
Our ability to easily adopt and effectively apply new manufacturing technologies, as well as a general ability of the nation to create and produce will absolutely define the future of Serbia.

Having in mind the above described, the process of industrialization as well as the process of European integrations, although at its very beginnings and far from being completed, require that appropriate and effective instruments of technology transfer should be developed and promptly implemented in practice. This paper is an attempt do define a generic model to regulate this field and set this topic into the context of European integration processes of Serbia. The model is presented in Figure 14 and it identifies two strata for technology transfer: the science stratum and the economy stratum. Further, two basic subdomains are identified, the national framework of Serbia and the European Union which Serbia wishes to become part of, with a complex process that stretches through these two domains and whose primary goal is the integration of Serbia into the community of European nations. In such a context, the overall research domain of Serbia can play a key role in the industrialization process of Serbia's economy through initiating a dynamic and effective technology transfer process as well as the process of know-how knowledge and skills transfer.

The economic stratum is that of horizontal technology transfer through imports of technology - purchasing of modern equipment, foreingn investments or cooperative arrangements, including licences. This is a typical framework of developed economies-developing economies interaction. This is also a channel for the transfer of insuficiently formalized knowledge, namely, tacit knowledge, which puts the technology acceptor into a rather difficult position.

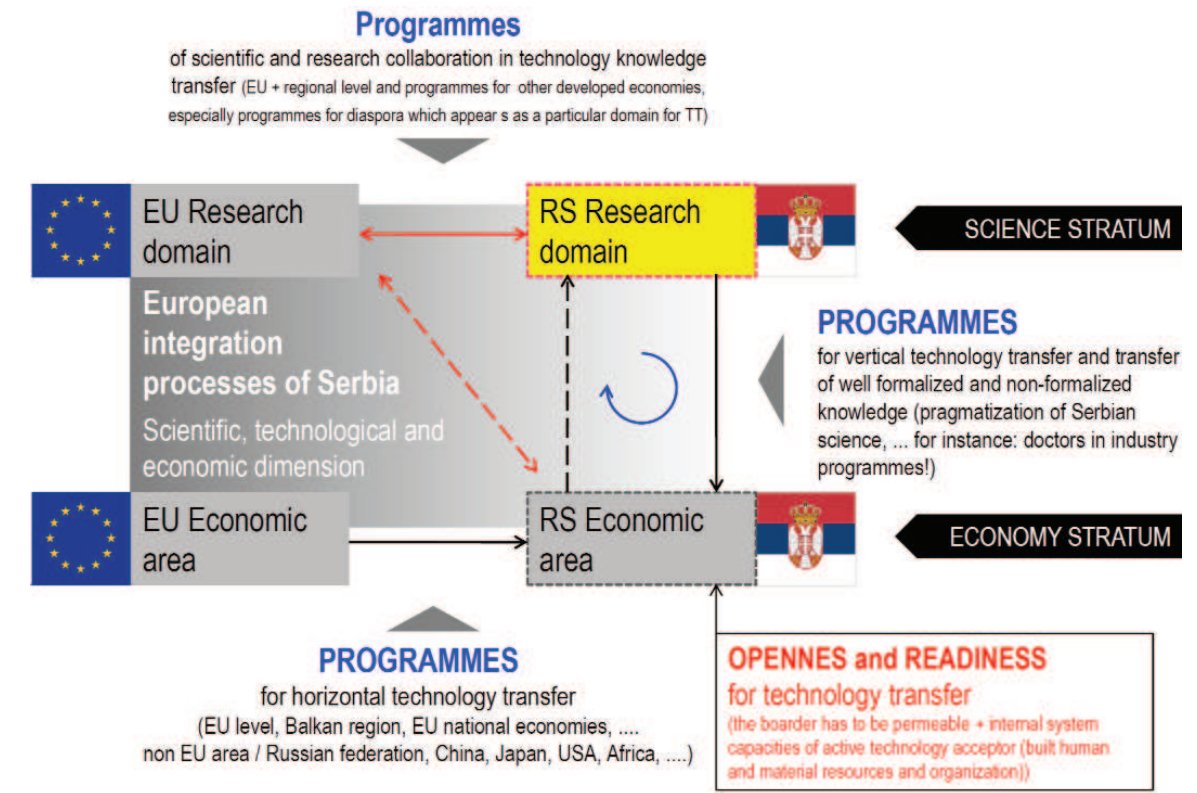

Figure 14: Technoeconomic dimension of the European integration processes of Serbia and the industrialization process: a general model for technology transfer and for transfer of know-how knowledge and skills.

In the developed economies, technology transfer is carried out through the interaction between the economic and the research and development strata. This is a vertical technology transfer, of bidirectional character in its full capacity (technology and know-how generator is not only the donor but also the acceptor who, in case of well organized programme framework, returns to the research and development stratum a non-formalized complex of knowledge that includes experience and elements of practical valuation of contents the donor sent to the economic stratum). An innovation- based economy, the European union [3], brings the vertical technology transfer to the highest level of social priority and supports, stimulates and intensifies it with a broad, well conceived and implemented set of instruments and programmes, the most important of which are the European Technology Platform Programme, instruments of private and public partnership for the valley of death, HORIZON 2020 with its three strategic priorities, etc., including the appropriate institutional framework (European Institute for Innovation and Technology - EIT, for example). 
In addition to the horizontal transfer of technologies that is realized more or less intensively within the economy stratum, the European integration process is a great opportunity for Serbia to realize a horizontal transfer of technologies and know-how through the science stratum. In contrast to the horizontal technology transfer in the economic stratum, the technology transfer in the science stratum has a generic nature, carrying a tremendous developmental potential for the Serbian industry. This communication channel is dominantly based on the formalized knowledge transfer, therefore it is manageable and easy to follow. In order that the horizontal technology transfer through the science stratum be valuated, it has to reach the economy stratum of Serbia. Hence, besides being more substantial and more relevant, this form of technology transfer is considerably more complex, since in addition to the horizontal, it requires a vertical communication channel.

In such a context of indirect technology transfer and the know-how transfer, Serbia becomes a sort of knowledge broker, an active agent that can use the Samuelson effect of technology convergence to create a technology and time shortcut in its industry development and thus promptly recover the two lost decades in its development. To accomplish this role, the science of Serbia should in the first place become open and ready for such a delicate and responsible role. At present, the science in Serbia is not ready for this, both from the aspect of research and development infrastructure, of organization and of human resources; moreover, the state even does not have appropriate programmes oriented towards the relevant needs of its industry to be funded from its extremely small budget earmarked for scientific and technology development. At the moment, science in Serbia is confined within itself, with very poor, and in many aspects non-existent connections with the industry and economic systems in general.

The conditions in the economy stratum are similar. The industry of Serbia, a typical factory in Serbia, are closed to science and innovation. Factories established through foreign investments almost entirely realize their development component outside the economic domain of Serbia. Corporate managers responsible for the business system of Serbian factories are almost exclusively engaged in resolving elementary existential issues, and build their competitive position through cost reduction, especially in the domain of workforce, designing the business system in such a manner that human resources are dominantly oriented towards work-intensive jobs.

The above stated conclusions are strongly corroborated by the report of the World Economic Forum on Global Competitiveness of the Serbian economy, held in 2013, which ranked Serbia as 101st out of 148 national economies. The metrics was derived in a twelve-dimensional space (Figure 14 and Table 2), structured in each dimension [35]:
1. Institutions,
2. Infrastructure,
3. Macroeconomic environment,
4. Health and primary education,
5. Higher education and knowledge innovation,
6. Goods and service market efficiency,
7. Labour market efficiency,
8. Financial market development,
9. Technological readiness,
10. Market size,
11. Business sophistication,
12. Innovation.

\section{This metric space is not octogonal.}

The poorest performance of Serbia is perceived in the innovation dimension, in which the country is ranked 137th in the global economic system. In the interval from 1 to 7 points used to weight the innovation capacity, Serbia scored only 2.9 points, far below average. Although considerably higher, the capacity in the domain of tertiary education is not satisfactory, since with its 4 points Serbia is ranked in the middle of the 1-7 point scale, which further points out that our stereotype about educated labour force in this country is essentially wrong, namely, that the processes going on in this domain display a negative gradient. A complete profile for all the twelve dimensions of the metrics for national competitiveness is presented in Figure 15, and the structure of the dimensions 5,9 and 12 , that is, tertiary education, technological readiness and innovation, respectively, is given in Table 2. 


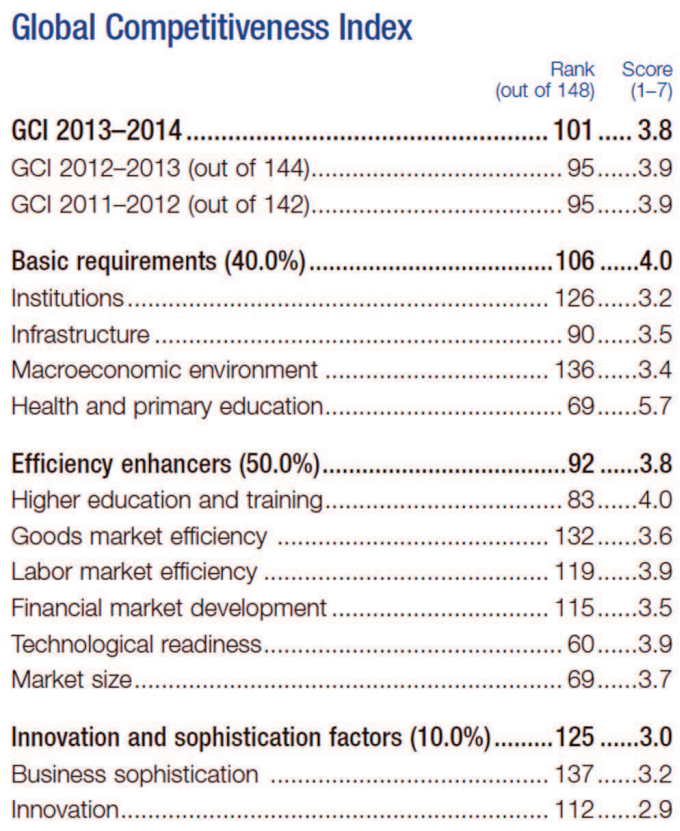

Stage of development

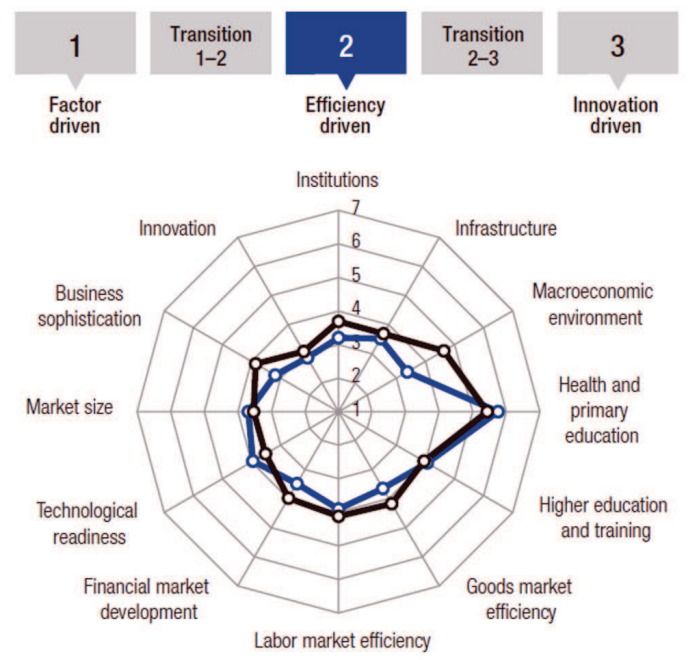

- - Serbia $\quad-0$ - Efficiency-driven economies

Figure 15: Serbian national competitiveness index profile defined by twelve-dimensional metrics according to the Global Competitiveness Report 2013-2014. Data for Serbia are generated by the Foundation for the Advancement of Economics (FREN) [35].

The essence is in that Serbia has to build a complex system of technology transfer programmes, after the above proposed model, whose structure is presented in Figure 15. Such a programme complex would pragmatize the Serbian science and orient it towards activities highly relevant for the industrial and economic system. It would also guide Serbia towards the knowledge-based society (a new role of science as a generator of developmental processes and the development of society in general). Such a technology transfer system would be a composit of three groups of programmes set into the European integration process of Serbia:

1. Programmes for horizontal transfer in the science stratum - programmes of scientific and research collaboration (the EU + regional level and programmes for other distant locations of developed economies, especially programmes for the diaspora which is one of specific frameworks for an efficient technolgy transfer)

2. Programmes for the vertical technology transfer in the national framework - programmes for the transfer of formalized and non-formalized knowledge through domestic science - domestic industry interaction (pragmatization of Serbian science, bidirectional processes mechanisms, ... especially the doctors in industry programme package!)

3. Programmes for the horizontal technology transfer in the economy stratum - industrial cooperation in the EU framework, as well as in the frameworks of the Balkan region, the EU national economies (e.g., cooperation with Italy on the Fiat Auto Serbia project), interaction with the non-EU area / Russian Federation, China, Japan, the USA.

The above explained set of technology transfer programmes should be complemented with special programmes for building openness and readiness of Serbia for technology transfer processes on both strata. 
Table 2: Performance of Serbia profile in the domain of tertiary education, technological readiness and innovativeness according to The Global Competitiveness Report 2013-2014 (areas marked green denote the domain of relative comparative advantage, those marked yeallow denote a relative comparative weakness) [35].

\begin{tabular}{l|lll|}
\hline Dimension & Indicator & Value & Rank / 148 \\
\hline 5 th Dimension & Higher education and training & 4.0 & 83 \\
5.01 & Secondary education enrollment, gross \%* & 91.5 & 62 \\
5.02 & Tertiary education enrollment, gross \%* & 50.4 & 50 \\
5.03 & Quality of the educational system & 3.1 & 111 \\
5.04 & Quality of math and science education & 4.3 & 55 \\
5.05 & Quality of management schools & 3.6 & 114 \\
5.06 & Internet access in schools & 3.9 & 84 \\
5.07 & Availability of research and training services & 3.4 & 121 \\
5.08 & Extent of staff training & 3.0 & 140 \\
9 th Dimension & Technological readiness & 3.9 & 60 \\
9.01 & Availability of latest technologies & 4.1 & 118 \\
9.02 & Firm-level technology absorption & 3.7 & 137 \\
9.03 & FDI and technology transfer & 3.9 & 115 \\
9.04 & Individuals using Internet, \%* & 48.1 & 67 \\
9.05 & Fixed broadband Internet subscriptions/100 pop.* & 10.2 & 61 \\
9.06 & Int'l Internet bandwidth, kb/s per user* & 70.5 & 29 \\
9.07 & Mobile broadband subscriptions/100 pop. * & 40.2 & 41 \\
12 th Dimension & Innovation & 2.9 & 112 \\
12.01 & Capacity for innovation & 2.8 & 133 \\
12.02 & Quality of scientific research institutions & 3.7 & 66 \\
12.03 & Company spending on R\&D & 2.5 & 127 \\
12.04 & University-industry collaboration in R\&D & 3.2 & 104 \\
12.05 & Gov't procurement of advanced tech products & 2.8 & 123 \\
12.06 & Availability of scientists and engineers & 3.9 & 85 \\
12.07 & PCT patents, applications/million pop.* & 2.8 & 53 \\
\hline
\end{tabular}

In order that programmes for the systemic transfer of technologies and know-how be effective and that they should stimulate an accelerated development of industry, it is necessary that a realistically achieved level of industry development in Serbia be taken into account. The economic system of Serbia is dominantly in the range of the so-called efficiency driven economy (M. Porter's classification of the economic system development [36]). The real state of the art of the industry system is probably even more unfavourable. Objectively, Serbia is really far from its final objective, the innovation-driven economy, therefore our innovation system relevant for industry development has to be designed in such a manner that it should focus on the LMT sector and incremental innovation processes based on an intensive implementation of advanced manufacturing technologies and industrial information and communication technologies, in order that it should primarily foster the growth in manufacturing processes efficiency and achieve the necessary growth on this bases - the quantitative growth. The focus upon generic technologies (nanotechnologies, new materials, ...) ranked in the set of research priorities within the current strategy of research and technology development of Serbia cannot be valuated in a measure relevant for Serbia, regardless of the results acheved by the science stratum, due to its being in a collision with the conditions in the economy stratum, namely, its ability to adopt such technologies and valuate them efficiently in the market. It is in this context that the National Technology Platform Programme can play a significant role due to its inherent collusion with industry and with the European research area.

The European integration process also has its technology dimension, however, Serbia is yet to discover it. 


\section{REFERENCES:}

[1] Strategija i politika razvoja industrije Republike Srbije od 2011. do 2020. godine, Vlada Republike Srbije, Jun 2011. godine.

[2] Serbia 2020: Koncept razvoja Republike Srbije do 2020. godine, Radna verzija, Beograd, 2010.

[3] European Commission, EUROPE 2020 - A strategy for smart, sustainable and inclusive growth, Brussels, Communication from the Commission COM(2010) 2020, 03.2010.

[4] European Commission, AN INTEGRATED INDUSTRIAL POLICY FOR THE GLOBALISATION ERA - Putting Competitiveness and Sustainability at Front Stage, Communication from the Commission to the European Parliament, the Council, the European Economic and Social Committee and the Committee of the Regions, $\operatorname{COM(2010)~614,~Brussels,~01.2010.~}$

[5] Commission of the European Communities: INDUSTRIAL POLICY IN AN ENLARGED EUROPE - Communication from the Commission to the Council, the European Parliament, the Economic and Social Committee and the Committee of the regions, Brussels, 12.2002, com (2002) 714 final.

[6] European Commission, 2020 by 2020 - Europe's climate change opportunity, Communication from the Commission to the European Parliament, the Council, the European Economic and Social Committee and the Committee of the Regions, $\operatorname{COM(2008)~} 30$ final, Brussels, 01.2008.

[7] Renewable Energy Technology Roadmap $20 \%$ by 2020, EREC - European Renewable Energy Council, 2008.

[8] Communication from the Commission to the European Council, A EUROPEAN ECONOMIC RECOVERY PLAN, Brussels, 26.11.2008, COM(2008) 800 FINAL.

[9] European Commission, Directorate-General for Research, European Research Area Knowledge-based economy, STRENGTHENING THE ROLE OF EUROPEAN TECHNOLOGY PLATFORMS IN ADDRESSING EUROPE'S GRAND SOCIETAL CHALLENGES - Report of the ETP Expert Group, October 2009, EUR 24196 EN.

[10] Lund Declaration, "Europe Must Focus on the Grand Challenges of our Time", Swedish EU Presidency, July 2009, Lund, Sweden.

[11] European Commission, FOURTH STATUS REPORT OND EUROPEAN TECHNOLOGY PLATFORMS Harvesting the Potential, Directorate-General for Research, 2009, EUR 23729 EN.

[12] European Commission, TECHNOLOGY PLATFORMS - From Definition to Implementation of a Common Research Agenda, Report compiled by a Commission Inter-Service Group on Technology Platforms, Directorate-General for Research, Directorate B - Structuring the European Research Area, 2004, EUR 21265.

[13] Commission of the European Communities, REPORT ON EUROPEAN TECHNOLOGY PLATFORMS AND JOINT TECHNOLOGY INITIATIVES - Fostering Public-Private R\&D Partnerships to Boost Europe's Industrial Competitiveness, Brussels, 10.6.2005,SEC(2005) 800.

[14] Roadmap: Factories of the Future beyond 2013 - Consultation document, EFFRA - European Factories of the Future Research Association, Brussels Belgium, Jun 2011.

[15] Aschhoff, B., Crass, D., Cremers, K., Grimpe, C., and Rammer, C., European Competitiveness in Key Enabling Technologies - FINAL REPORT, Centre for European Economic Research (ZEW), Mannheim, Germany, 2010.

[16] European Commission, Directorate-general for Research, Directorate G - Industrial Technologies, FACTORIES OF THE FUTURE - PPP Strategic Multi-annual Roadmap, 2010, ISBN 978-92-79-15227-6.

[19] Jovane, F., Westkämper, E., and Williams, D., THE MANUFUTURE ROAD - Towards Competitive and Sustainable High-Adding-Value Manufacturing, 2009, Springer-Verlag Berlin Heidelberg, ISBN 978-3540-77011-4.

[20] Jovane, F., Koren, Y., and Boer, C.R., Present and Future of Flexible Automation: Towards New Paradigms, CIRP Annals - Manufacturing TechnologyVolume 52, Issue 2, 2003, pp 543-560.

[21] Ueda, K., and Markus, A., and Monostori, L. and and Arai, T. (2001) Emergent Synthesis Methodologies for Manufacturing. CIRP Annals, 50 (2). pp. 535-551. ISSN 0007-8506.

[22] Jovane, F., Yoshikawa, H., Alting, L., at all, The incoming global technological and industrial revolution towards competitive sustainable manufacturing, CIRP Annals - Manufacturing Technology Volume 57, Issue 2, 2008, Pages 641-659.

[23] European Commission, Directorate-general for Research, Directorate C - European Research Area: Knowledge-based economy, A KNOWLEDGE-INTENSIVE FUTURE FOR EUROPE - Expert Group Report, October 2009, ISBN 978-92-79-13820-1.

[23] European Commission, Directorate-General for Research, Manufuture High Level Group, MANUFUTURE - A VISION FOR 2020, November 2004, Brussels, ISBN 92-894-8322-9, 
[24] Manufuture High Level Group and Support Group and Collaboration with Emerging Production Paradigms Laboratory (EPP Lab of ITIA-CNR, Italy), ManuFuture Platform - STRATEGIC RESEARCH AGENDA - Assuring the future of manufacturing in Europe, July 2006, Brussels.

[25] MANUFUTURE Implementation Support Group (ISG), Green Paper "From Challenges to Opportunities: Towards a Common Strategic Framework for EU Research and Innovation funding", MANUFUTURE European Technology Platform's Contribution to Public Consultation, May 2011.

[25] European Commission C(2010)4900, Work programme 2011, Cooperation, Theme 3, ICT - INFORMATION AND COMMUNICATIONS TECHNOLOGIES, Brussels, 2010.

[26] European Commission, COM(2012) 582 final, COMMUNICATION FROM THE COMMISSION TO THE EUROPEAN PARLIAMENT, THE COUNCIL, THE EUROPEAN ECONOMIC AND SOCIAL COMMITTEE AND THE COMMITTEE OF THE REGIONS, A Stronger European Industry for Growth and Economic Recovery, Industrial Policy Communication Update, Brussels, 10.10.2012.

[27] Jeremy Rifkin, The Third Industrial Revolution - How lateral power is transforming energy, the economy, and the wrld, Palgrave and Macm, New York, USA, 2011, ISBN: 978-0-230-11521-7.

[28] B. Joseph Pine II, Mass Customization: The New Frontier in Business Competition, Harvard Business School Press (January 1999), ISBN-10: 0875849466

[29] G. von Krogh, K. Ichijo, and I. Nonaka, How to Unlock the Mystery of Tacit Knowledge and Release the Power of Innovation, Oxford University Press, New York and Oxford, 2000. ISBN-10: 0195126165

[30] Chesbrough, H.W., Open Innovation: The new imperative for creating and profiting from technology, Boston: Harvard Business School Press, (2003), ISBN-10: 1578518377.

[31] Davies, S., Future Perfect, Addison Wesley Publishing Company, 1987, ISBN: 0-201-59045-X.

[32] G. von Krogh, K. Ichijo, and I. Nonaka, Enabling Knowledge Creation: How to Unlock the Mystery of Tacit Knowledge and Release the Power of Innovation Oxford University Press, New York and Oxford, 2000.

[33] Hartmut Hirsch-Kreinsen, David Jacobson and Paul Robertson (editors), "Low-Tech" Industries: Innovativeness and Development Perspectives - A Summary of a European Research Project PILOT Project Consortium, December 2005

[34] Organisation for Economic Cooperation and Development - OECD, Frascati Manual: THE MEASUREMENT OF SCIENTIFIC AND TECHNOLOGICAL ACTIVITIES - Proposed Standard Practice for Surveys on Research and Experimental Development, 2002, ISBN 92-64-19903-9.

[35] Schwab, K., THE GLOBAL COMPETITIVENESS REPORT 2013-2014: Full Data Edition, published by the World Economic Forum within the framework of The Global Competitiveness and Benchmarking Network, 2013, ISBN-13: 978-92-95044-73-9.

[36] Porter, M.E. The Competitive Advantage of Nations, The Free Press: New York, 1998, ISBN 9780684841472.

Receieved: November 2013. Accepted: March 2014.

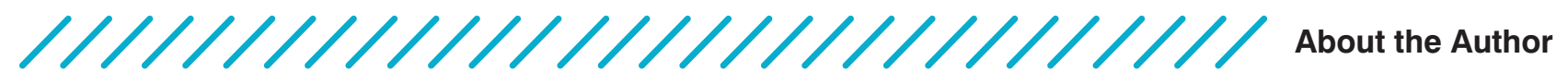

Petar B. Petrović

Belgrade University, Faculty of Mechanical Engineering pbpetrovic@mas.bg.ac.rs

Petar B. Petrović is full professor at the Faculty of Mechanical Engineering, University of Belgrade. He received his PhD degree in 1994 in the field of production engineering, manufacturing technology and robotics. Since 1984 he has been employed at the Production Engineering Department of the Faculty of Mechanical Engineering, University of Belgrade. He was an active participant in over 40 development projects of cooperation with the economy of Serbia, on the tasks of new technology implementation and manufacturing processes modernization. He published over 150 papers in national and international journals and at scientific and expert conferences. Mr Petrović is a full member of the Academy of Engineering Sciences of Serbia - AINS, where he manages the programme of the National Technology Platform of Serbia, NTPS Program, which is a strategic priority and hence a constituent part of the current Strategy of industrial development of Serbia from 2010 till 2020. He is married and has three children.

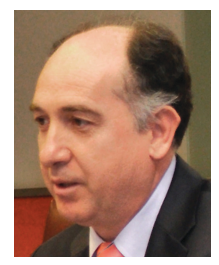

